\title{
X-ray metrology for advanced microelectronics
}

C. Wyon ${ }^{\mathrm{a}}$

CEA-LETI, Minatec, 17 rue des Martyrs, 38054 Grenoble, France

Received: 31 July 2009 / Accepted: 25 November 2009

Published online: 26 January 2010 - (C) EDP Sciences

\begin{abstract}
The recent development of bright X-ray sources, reliable X-ray focusing optics, large X-ray detectors and X-ray data modelling and processing, have improved X-ray techniques to the point where many are being introduced in MOS transistor manufacturing lines as new metrology methods. The fundamental $\mathrm{X}$-ray physical properties, such as their small wavelength and their weak interaction with solid-state matter satisfy basic in-line metrology requirements: non-destructiveness, speed, accuracy, reliability and long-term stability. The capability of X-ray based metrology methods to monitor critical 65 and $45 \mathrm{~nm}$ processes such as ion implant, nitrided $\mathrm{SiO}_{2}$ gate dielectrics, $\mathrm{NiSi}, \mathrm{Cu} /$ porous low- $\kappa$ interconnects and MIM capacitors is highlighted in this paper.
\end{abstract}

\section{Introduction}

Continuous shrinking of MOS transistors, also known as Moore's law, requires nowadays the use of new materials that exhibit electrical characteristics that are quite different than those of conventional silicon-based materials such as polycrystalline $\mathrm{Si}, \mathrm{SiO}_{2}, \mathrm{Si}_{3} \mathrm{~N}_{4}$ and $\mathrm{Al}$ interconnects. From the $120 \mathrm{~nm}$ to the $32 \mathrm{~nm}$ MOS generation, materials with a low and/or high dielectric permittivity (low- $\kappa$ and high- $\kappa$ ), metal gates, Damascene $\mathrm{Cu}$ interconnects, nickel silicide, strained layers... have been gradually integrated in microelectronic devices.

MOS transistors are now manufactured using an evergrowing number of thin films. Moreover, their thickness tends to decrease with the downsizing of MOS dimensions. Accordingly, the physical and chemical phenomena occurring at the various film interfaces become more and more important because they can considerably affect the MOS transistor properties.

While conventional metrology was mainly devoted to measuring film thicknesses and pattern critical dimensions (CD) for $120 \mathrm{~nm}$ technology and above, the monitoring of thin films and interface "chemical compositions" at the atomic scale becomes compulsory for the $90 \mathrm{~nm}$ MOS generation and beyond. "Chemical composition" does not only mean the real chemical composition of thin films and interfaces but can also include their crystalline phases, their texture, the micro-structure of their porosity, the density and size of pores and crystalline defects resulting from ion implant...

Metrology techniques based on X-ray radiation are now commonly used to monitor production and development of advanced microelectronic devices. X-ray radiation exhibits basic characteristics which make it very

\footnotetext{
a e-mail: cwyon@cea.fr
}

suitable for the metrology of advanced MOS transistors: (i) the X-ray wavelength is similar to the feature size being measured; (ii) the interactions between X-ray and solid state matter are weak and non-disturbing enabling nondestructive analysis; (iii) the X-ray optical constants are known for all materials; (iv) the measurement is traceable to international standards.

Significant improvements in X-ray sources, optics, $2 \mathrm{D}$ detectors and X-ray data modelling and processing have been possible thanks to the recent development of large synchrotron facilities. As a result, a 30 to $50 \mathrm{~nm}$ spatial resolution has been achieved for both the soft X-ray (up to few $\mathrm{keV}$ ) and the hard X-ray (higher than $10 \mathrm{keV}$ ) regimes for three-dimensional characterization [1,2], as well as a $200 \mathrm{~nm}$ X-ray spot size for X-ray diffraction [3] by using bright synchrotron X-ray sources. It is nonetheless important to note that the use of bright monochromatic and focused X-ray radiation from a synchrotron source can damage the thin top Si layers of SOI structures [4].

Many X-ray based methods are well adapted to monitor the manufacturing of microelectronic processes, for example, X-ray fluorescence (XRF), X-ray reflectivity (XRR), grazing incidence small angle X-ray scattering (GI-SAXS), X-ray photoelectron spectroscopy (XPS), $\mathrm{X}$-ray diffraction (XRD) and its parent technique X-ray diffraction topography (XRT). Many of the monitoring needs of the MOS manufacturing process can be satisfied by using a combination of these X-ray techniques. Thus, critical parameters such as film and interface thickness, chemical composition, strain and stress in thin film stacks, pore microstructure parameters and crystalline structure, can be accurately and recurrently controlled.

This paper reviews the positive impact of X-ray metrology on the development of 65 and $45 \mathrm{~nm}$ MOS transistors. 


\section{Basic metrology requirements}

In the International Technology Roadmap for Semiconductors [5], metrology is defined as measurements that are done in situ, in-line and off-line. In situ metrology deals with measurements and process control performed inside the process chamber. In-line metrology refers to measurements and process control performed inside the clean-room, while off-line metrology refers to measurements done outside the clean-room; off-line metrology generally concerns material characterization and customer return parts analysis.

This paper is concerned mainly with in-line X-ray metrology, but will also present some results obtained by using off-line X-ray metrology techniques.

In a silicon semiconductor manufacturing and development line, metrology is required for: (i) the fast development and manufacturing of new processes: the learning cycle must be as short as possible in order to quickly achieve high production yields; (ii) the fast recovery of process equipment after preventive or curative maintenance, to ensure that this process step will not degrade MOS transistor properties nor manufacturing yields; (iii) tool matching, to make sure that different tools can reliably perform the same process; and (iv) the detection of process excursions, which can alter electrical MOS transistor performances and lower the manufacturing yield.

The metrology activity will obviously depend on the maturity of processes to be controlled, and of the process integration in a specific circuit [6]. When new materials are integrated in a microelectronic device, their basic physical and chemical properties (thickness, chemical composition, crystalline structure, grain size) need to be perfectly controlled, as do the evolution of these properties and of the experimental conditions (deposition and etch rates, for instance) as a function of process parameters (temperature, gas flow...). The issues related to the integration of new materials in transistors (thermal and chemical reactivity with the underneath and above layers) must be carefully investigated. Preliminary analyses are generally achieved using unpatterned monitoring wafers during the process development stages. Subsequently, measurements are performed using patterned wafers. Dedicated metrology structures are designed and manufactured around the electrical test structures to study the process integration issues related to these new materials, as well as the impact on MOS transistor properties and manufacturing yield. Typical metrology structures are 50 to $70 \mu \mathrm{m}$ wide and can be as long as $1 \mathrm{~mm}$ for some dedicated measurements. These dimensions tend to decrease as MOS transistors get smaller because the silicon surface becomes more and more expensive.

The needs for metrology and process control decrease as process integration reaches maturity, since one gradually get knowledge about new materials and processes. As a result, only the metrology activities associated with processes which are considered critical for the MOS manufacturing yield will remain compulsory.

Specific requirements related to the development and manufacturing processes of MOS transistors lead to im- portant constraints for the metrology techniques: (i) they must be non-destructive and non-intrusive; (ii) the basic measurement principle must be as representative as possible of the final MOS electrical properties; (iii) each measurement must take as little time as possible - the targeted metrology wafer throughput should be around 60 wafers per hour; (iv) the measurement spot size must comply with the metrology test structure size $(50-70 \mu \mathrm{m})$; (v) the measurement must be repeatable, reliable, stable and accurate; (vi) the in-line tool must be equipped with automated pattern recognition features and hardware to enable its connection to the manufacturing line automation system.

\section{$3 \mathrm{X}$-ray metrology-basics and experimental instruments}

This section describes the basic principles of the X-ray metrology techniques dedicated to the control of new processes developed for 65 and $45 \mathrm{~nm}$ microelectronic devices.

\subsection{Grazing incidence small angle $X$-ray scattering (GI-SAXS)}

X-ray scattering represents the change in energy and in propagation direction of an X-ray photon interacting with an atom. It can be specular when the X-ray beam is reflected at an angle identical to the incident angle, or diffuse when the X-ray radiation is scattered in all directions. Grazing incidence small angle X-ray scattering (GI-SAXS) is commonly used for the characterization of micro- and nano-structures such as porous layers [7], precipitates and quantum dots [8].

For the aforementioned applications, the GI-SAXS method consists in recording the X-ray scattered radial distribution as a function of the X-ray incident angle (Fig. 1). The GI-SAXS technique available for monitoring the pore microstructure properties of low- $\kappa$ layers is mainly based on the "rocking-scan" method [9]. Nevertheless that the experimental set-up avoids the use of any moving part; the variation of the incidence angle arises from the divergence of the incident X-ray beam, which leads to very fast measurements compared to the conventional GI-SAXS methods. The incident angle typically ranges from 0.1 to $0.5^{\circ}$ depending on the investigated film stack, while scattering angles from 0 to $10^{\circ}$ can be captured by the large area detector. The typical measurement time is 400 to $600 \mathrm{~s}$ per point.

\subsection{X-ray reflectivity (XRR)}

$\mathrm{X}$-ray reflectivity is a specific case of X-ray scattering that occurs at the interface between two layers exhibiting different refractive indices. The refractive index of materials in the X-ray spectral range can be expressed as:

$$
n=1-\delta+i \beta,
$$




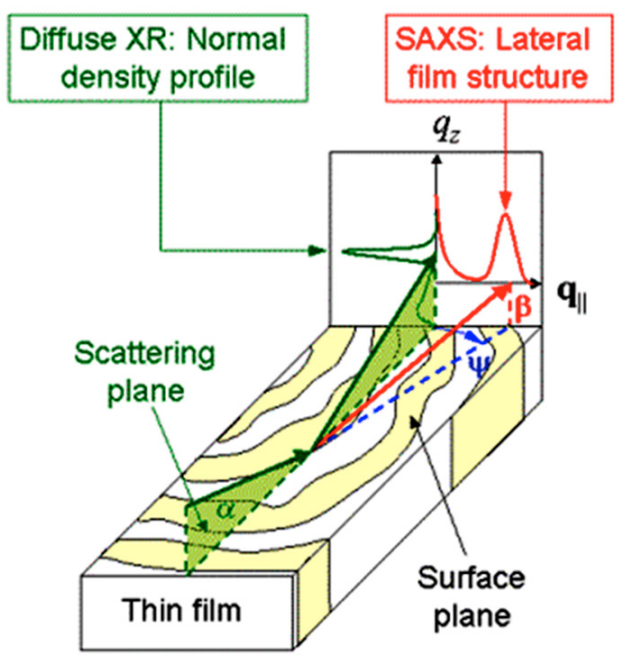

Fig. 1. (Color online) Basic principle of the GI-SAXS technique.

in which $\delta$ and $\beta$ are characteristics of the dispersion and absorption of X-rays. $\delta$ and $\beta$ are very weak: around $10^{-5}$ to $10^{-6}$, respectively. When the layers are homogeneous and the X-ray wavelength is far from the absorption bands of the constitutive elements, $\delta$ and $\beta$ can be expressed as:

$$
\begin{aligned}
& \delta=\frac{\lambda^{2}}{2 \pi} r_{e} \rho_{e}=\frac{\lambda^{2}}{2 \pi} r_{e} \frac{Z \rho N_{\mathrm{A}}}{M_{\mathrm{A}}} \\
& \beta=\frac{\lambda}{4 \pi} \mu,
\end{aligned}
$$

in which $\lambda$ is the $\mathrm{X}$-ray wavelength, $r_{e}$ the Bohr atomic radius, $\rho_{e}$ the electronic density of the material, $Z$ the atomic number, $\rho$ the mass-density, $N_{\mathrm{A}}$ Avogrado's number, $M_{\mathrm{A}}$ the atomic mass and $\mu$ the material linear absorption coefficient at the considered X-ray wavelength.

In the X-ray spectral range, the refractive index of any material is, thus, very close to 1 . Consequently, the $\mathrm{X}$-ray beam is always refracted far from the normal to the sample surface. When the $\mathrm{X}$-ray incident angle is nearly $0^{\circ}, \mathrm{X}$-rays do not penetrate inside the material; the $\mathrm{X}$-ray beam is totally reflected. This fundamental property of X-rays is used for the determination of metallic impurity concentration in silicon using total X-ray fluorescence (TXRF) [10]. In this case the $\mathrm{X}$-ray beam is propagating parallel to the sample surface. This phenomenon occurs until the X-ray incidence angle reaches a critical value $\theta_{c}$, the critical angle. The critical angle can be calculated using Snell's law:

$$
\theta_{c}=\sqrt{2 \delta}=\sqrt{\frac{\lambda^{2}}{\pi} r_{e} \frac{Z \rho N_{\mathrm{A}}}{M_{\mathrm{A}}}} .
$$

Once the basic parameters of the investigated layer, such as its atomic number and mass, are well known, the precise determination of the critical angle allows the direct measurement of mass and/or electron density.

When the X-ray incidence angle is greater than the critical angle $\theta_{c}$, X-rays penetrate the investigated layer, and are partially reflected by the sample surface and by

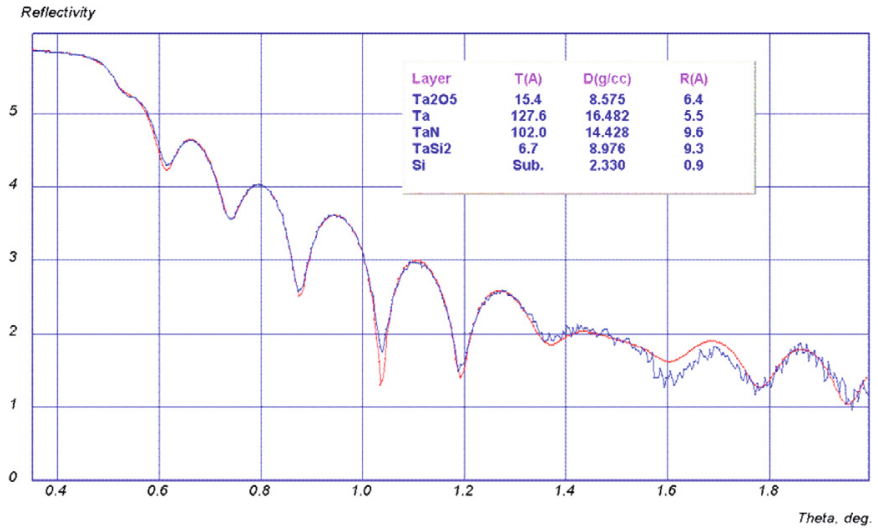

Fig. 2. (Color online) Experimental (blue) and modelled (red) XRR patterns of a PVD $13 \mathrm{nmTa} / 10 \mathrm{nmTaN}$ film deposited on $\mathrm{Si}$.

the interface(s) between the layer(s) and the substrate. Incident and refracted X-ray beams interfere together, and generate interferences in the XRR pattern called Kiessig fringes (Fig. 2). The period of the Kiessig fringes is directly proportional to the thickness of the investigated layer. Depending on the electron density contrast between the film and the substrate, the film thickness can be determined with an accuracy better than $0.1 \mathrm{~nm}$ using XRR.

Because the surface and/or interface roughness induces damping of the X-ray reflected intensity, XRR enables the independent measurement of several film properties: thickness, mass/electron density and surface/interface roughness.

Modelling the XRR patterns of thin films and film stacks is mandatory for determining the mass/electron density, the film thickness and the surface roughness. We have used Jordan Valley proprietary software, based on the recursive formalism first proposed by Parrat [11].

The X-ray metrology tool (Jordan Valley JVX6200) that has been used in this study is dedicated for $300 \mathrm{~mm}$ silicon wafers. It uses an original experimental set-up: $\mathrm{X}$-rays are emitted from a $\mathrm{Cu}-\mathrm{K}_{\alpha}$ source $(\lambda=0.156 \mathrm{~nm})$ in a wide incidence angle range, while reflected X-rays are detected using a bi-dimensional detector. The combined use of these features allows the measurement of film and film stack properties in a very short time: 10 to $100 \mathrm{~s}$ according to the film stack complexity and the desired accuracy. The X-ray spot size naturally depends on the incidence angle but is always smaller than $50 \mu \mathrm{m} \times 2 \mathrm{~mm}$.

\subsection{X-ray diffraction (XRD)}

X-ray diffraction occurs when X-rays interact with ordered structures such as crystalline lattices and nanostructure arrays. As a function of their incidence angle, X-rays reflected by the crystallographic planes can interfere in a constructive way, generating intense diffraction peaks. These diffraction peaks are characterized precisely to identify the nature and the allotropic phase of the constitutive elements in the layers, as well as the film texture and the biaxial strain in the layer [12]. 


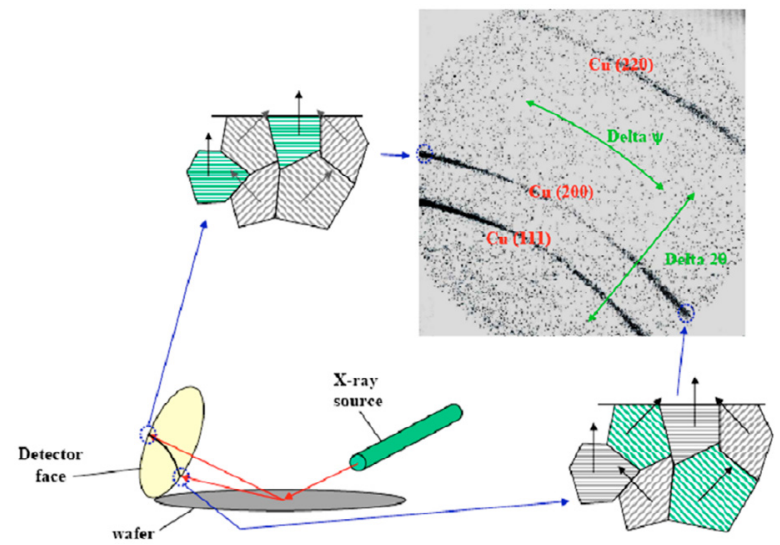

Fig. 3. (Color online) Experimental set-up of the XRD metrology tool. The area detector can capture multi-peaks at multiple tilt angles.

The main XRD tool (from Hypernex) we used in these studies can handle both 200 and $300 \mathrm{~mm}$ silicon wafers. The basic principle of this equipment is very simple (Fig. 3): (i) the X-ray beam with a spot size between $50 \mu \mathrm{m}$ and $1 \mathrm{~mm}$ and an incidence angle around $20^{\circ}$ is diffracted by the crystalline planes of the poly-crystalline film or film stack; (ii) the diffracted X-ray beams are intercepted by a 2D-detector, which must be very large in order to intercept a large number of X-ray diffracted beams.

We also used another XRD tool (from Bede) for some specific XRT analyses of silicon substrates after some critical process steps.

\subsection{X-ray fluorescence (XRF)}

The absorption of an X-ray photon by a thin layer can induce the ejection of an electron from a core level of one of the elements constituting the layer, due to the energy transfer between the incident photon and the electron cloud. Relaxation of the excited electronic states generated by photoemission can result in the emission of fluorescent X-ray photons. The X-ray fluorescence energy is characteristic of one of the elements constituting the layer.

The electronic transitions define a discrete spectrum of X-ray bands, which exhibit precise wavelengths or energies. As a matter of fact, each electronic transition is characteristic of specific energy levels and of the particular atom. The core electron energy levels involved in XRF are very deep, and are almost not affected by the local environment of the concerned atom; the XRF wavelength or energy of one element is unaffected by the local chemical and atomic environment of the emitting element and can be easily calibrated. Thus, the concentration of these elements can be determined, as well as the layer thickness, once the XRF intensity has been precisely calibrated. The $\mathrm{XRF}$ efficiency is almost equal to 1 for the $\mathrm{K}$ layers and increases with the atomic number of the fluorescent element.

The XRF experimental set-up we used for this study was integrated in the Jordan Valley JVX6200 tool [13]. It consisted of dedicated X-ray optics composed of specific capillaries that provided an incident X-ray beam with a 20 to $40 \mu \mathrm{m}$-spot size, and of silicon-based X-ray detectors, which are located close to the X-ray spot, to ensure very good collection efficiency.

The measurement time strongly depends on the fluorescence yield of the detected elements. It can be as short as $10 \mathrm{~s}$ per point for acquiring the whole XRF spectrum of heavy metallic elements.

\subsection{X-ray photoelectron spectroscopy (XPS)}

$\mathrm{X}$-ray photoelectron spectroscopy (XPS) is commonly used as a surface analysis technique to characterize chemical states of surfaces and interfaces, as well as to study the electronic structure of materials. XPS is based on the photoelectric effect, which results from the absorption of an X-ray photon. The X-ray photon transfers its energy to one electron, which is ejected from its orbital. The photoelectric effect can involve electrons from the valence and conduction bands, which are weakly bonded to the nucleus, but also the electrons from the core levels, which are more tightly bonded.

Photoelectrons arising from core levels correspond to transitions between a neutral atom $\mathrm{A}$ with $Z$ electrons to the final ion $\mathrm{A}^{+}$with $Z-1$ electrons, after the ejection of one photoelectron. XPS spectra consist of peaks (Fig. 4) which strictly correspond to the differences between the total energy of the initial state and the energies of the various final ionized states. The initial energy of the X-ray photon $h \nu$ is converted into $E_{i}$, the ionization energy for ejecting the electron from the atomic orbital, and into $E_{k}$, the kinetic energy transferred to the photoelectron:

$$
h v=E_{i}+E_{k} .
$$

Since the excitation energy $h \nu$ is well known, the measurement of the kinetic energy $E_{k}$ of the photoelectrons leads to a precise value of $E_{i}$, the binding energy of the ejected electron, which is characteristic of the atom and of the concerned core orbital.

The emission of photoelectrons results in a charged sample, since the atom $\mathrm{A}$ has been ionized to $\mathrm{A}^{+}$. The surface of a partially insulating and semiconducting sample will be positively charged by the photoelectric effect. Such a positive charge will slow down the photoelectrons and, consequently will shift and widen the XPS peaks. The determination of the chemical shift, which is defined as the binding energy difference between atoms bonded to different chemical species (for $\mathrm{Si}$ and $\mathrm{SiO}_{2}$ the chemical shift is $E_{\mathrm{Si}}^{4+}-E_{\mathrm{Si}}^{0}$, around $4 \mathrm{eV}$; see inset Fig. 4 ), becomes more delicate when the sample surface is charged.

The XPS peak intensity from a thin layer of thickness $d z$, localized at a depth $z$ below the sample surface, emitted according to an angle $\theta$ normal to the sample surface, can be expressed as a product of three terms which are characteristic of the photo-ionization process, the detection process and the ratio of photoelectrons transmitted through the sample $(z / \cos \theta)$ without any energy loss. This ratio can be expressed as [14]:

$$
\exp \left[-z /\left(\lambda_{l p m} \cos \theta\right)\right] \text {, }
$$




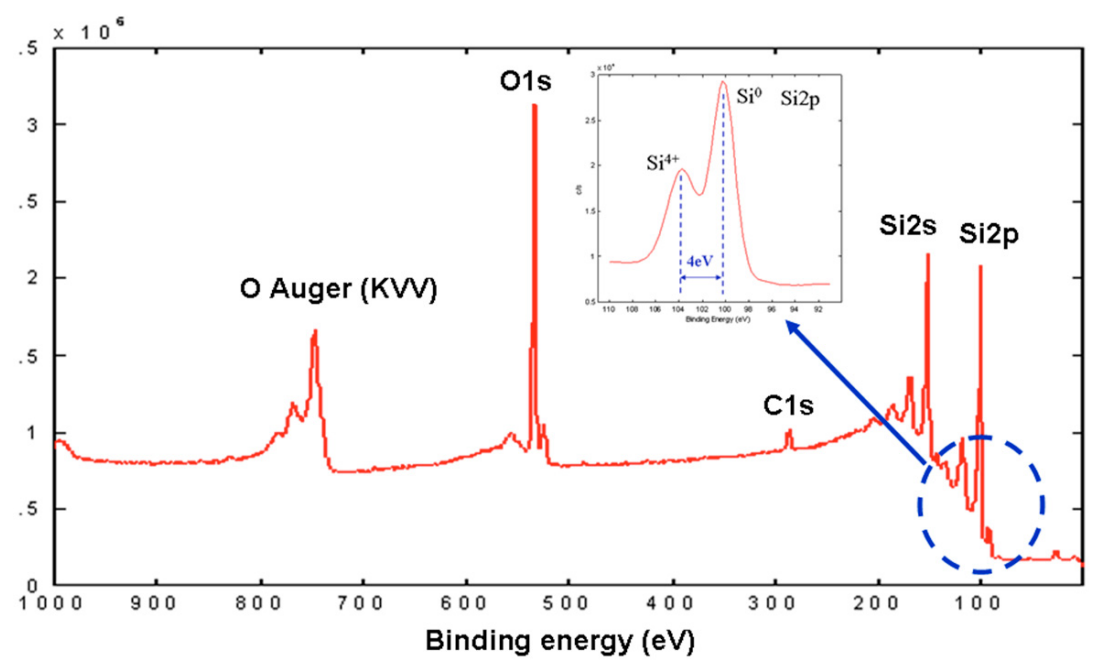

Fig. 4. (Color online) XPS spectra of a thin nitrided silicon oxide film on silicon.

where $\lambda_{l p m}$ is the photoelectron mean free path.

The integration of the variation of the XPS peak intensity as a function of $z$ demonstrates that the main part of the XPS signal arises from the emission at $z<3 \lambda_{l p m} \cos \theta$. Thus, the main part of the XPS signal is emitted from the first 2 to $10 \mathrm{~nm}$ below the sample surface for the conventional low X-ray energies used in XPS (Fig. 4).

During this study we used two different in-line metrology XPS tools from ReVera [15]. The first one (RVX1000) was dedicated to the process control on monitor wafers. The incident X-ray energy was $1253.6 \mathrm{eV}\left(\mathrm{Mg}-\mathrm{K}_{\alpha}\right)$ and the spot size close to $200 \mu \mathrm{m}$. The second tool (RVX3000) was dedicated to the process monitoring on $300 \mathrm{~mm}$ product wafers. Its incident X-ray energy was $1486.7 \mathrm{eV}\left(\mathrm{Al}-\mathrm{K}_{\alpha}\right)$ and its spot size was $35 \mu \mathrm{m}$. The typical measurement time for extracting film thickness and element dose from one XPS spectrum measured in the desired energy window is 60 to $150 \mathrm{~s}$ per site for both tools.

\section{$4 \mathrm{X}$-ray metrology of silicon substrate and ion implant}

Whatever the nature of the substrate used for manufacturing MOS transistors (Si single crystal or epilayer, SOI, and SiGe epilayer), the control of crystalline defects and thermo-mechanical stresses in the substrate is highly recommended. Crystalline defects can generate electrical traps, which can strongly impact the transistor performances. On the other hand, thermo-mechanical stresses can improve the mobility of charge carriers when the biaxial stress is applied according to a specific Si crystalline plane, enhancing in this way the transistor performances.

$\mathrm{X}$-ray diffraction techniques, such as high-resolution X-ray diffraction (HR-XRD) [16-18] and X-ray diffraction topography (XRT) [18] are perfectly suited for detecting and identifying the crystalline defects and quantifying the defect density. We have used an X-ray diffraction topography method to determine the process steps that generate crystalline defects during the whole MOS manufacturing process on bulk Si and SOI substrates.

The information provided by this X-ray topography is very interesting and can be used to tailor the process steps generating crystalline defects [19] (Fig. 5). Nonetheless, the time required for the full scanning of a $300 \mathrm{~mm}$ requires several hours is prohibitive; thus XRT can only be used as an off-line metrology tool.

Ion-implant is a manufacturing process that can generate crystalline defects which can be detrimental to the MOS transistor performances. These defects greatly impact the MOS transistor properties when they are close to very sensitive transistor areas like the MOS channel. This feature can occur during the ion implants of the source and drain areas, as well as during the LDD extension ionimplants (Fig. 6a).

Moreover, these defects can speed-up the diffusion of some metallic ions. For example, the diffusion of Ni species is enhanced due to the presence of crystalline defects and can lead to NiSi encroachment or the uncontrolled growth of nickel silicide between the gate and the source and/or drain [20]. To prevent this, specific ion-implant processes have been developed to prevent the creation of damaged or amorphous layers [21].

X-ray scattering-based techniques would appear to be useful metrology methods to characterize crystalline defects that are generated during ion implants [22-24]. In order to assess the capability of the GI-SAXS technique available on the ID02 beam line of the European Synchrotron Radiation Facility to detect crystalline defects, we prepared two silicon wafers. The wafers were implanted with $\mathrm{BF}_{2}$ ions at $15 \mathrm{keV}$ and doses equal to $36 \times 10^{15}$ at cm $^{-2}$ using two different experimental conditions and were then annealed under $\mathrm{N}_{2}$ at $800{ }^{\circ} \mathrm{C}$ (samples 3 and 4). TEM cross-sections revealed that sample 3 exhibited a defect density of 28 defects. $\mu \mathrm{m}^{-2}$ with an average defect size of $18.2 \pm 4.5 \mathrm{~nm}$, while the defect density and average defect size of sample 4 were 91 defects. $\mu \mathrm{m}^{-2}$ and $19.7 \pm 2.1 \mathrm{~nm}$ (Fig. $6 \mathrm{~b}$ ). 


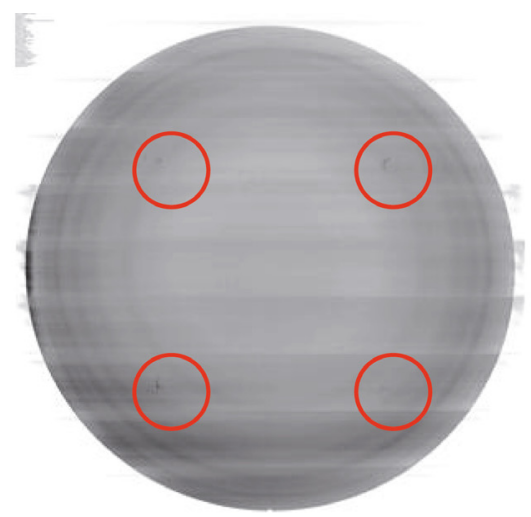

a) Si-low resolution transmission XRT

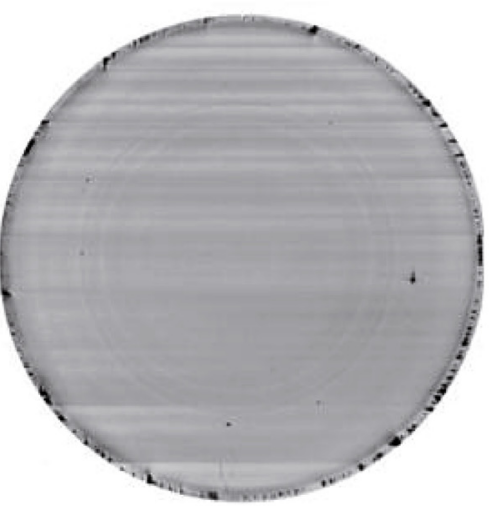

b) SOI-low resolution transmission XRT

Fig. 5. (Color online) X-ray transmission topography along (004) crystalline direction of $\mathrm{Si}$ (a) and SOI (b) substrates after MOS process steps [16].

After thinning the silicon wafers down to a $100 \mu \mathrm{m}$ thickness, transmission GI-SAXS patterns were obtained for samples 3 and 4 and for unimplanted silicon (hereafter referred as sample 2). The results revealed (Fig. 7) that: (i) samples 3 and 4 exhibit crystalline defects inducing X-ray scattering; (ii) the X-ray scattered intensity, for a scattering vector value $q$ around 4 to $5 \mathrm{~nm}^{-1}$, is identical for samples 3 and 4. This last observation suggests that the average defect size and defect density of samples 3 and 4 are equivalent. This result does not corroborate TEM analyses, which unambiguously pinpoint discrepancies between samples 3 and 4 .

In order to double-check the contradictory results obtained by GI-SAXS and cross-section TEM methods, the same samples were characterized using positron annihilation spectroscopy (PAS) at Ghent University. Characterization techniques based on positron annihilation are well adapted to unveil point defects in thin films [25]. PAS analyses confirmed the results obtained with the GI-SAXS method, namely that samples 3 and 4 exhibit the same defect density with a similar average defect size. The defects arise from the interaction between fluorine ions and vacancies $V$ of the silicon lattice leading to a correlated vacancy $F_{3 n} V_{2 n}$ defect with $n$ equal to 2 or 3 .

This study demonstrates that GI-SAXS analyses enable the characterization of crystalline defects after ion im-

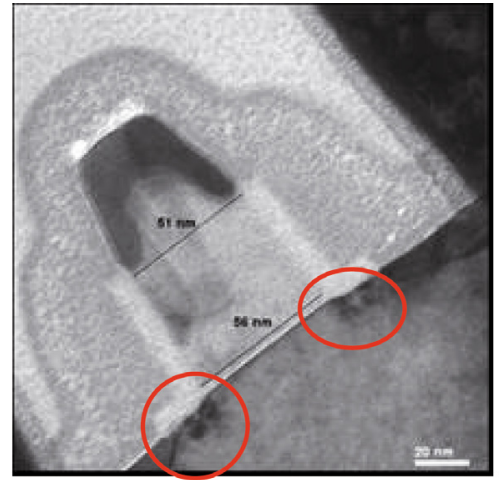

a) $65 \mathrm{~nm}$ transistor gate highlighting crystalline defects

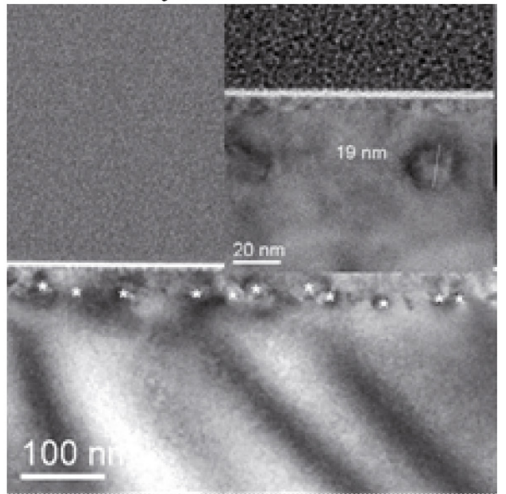

b) sample 4 - TEM lamella thickness: $210 \mathrm{~nm}$

Fig. 6. (Color online) TEM cross section of implanted samples presenting crystalline defects.

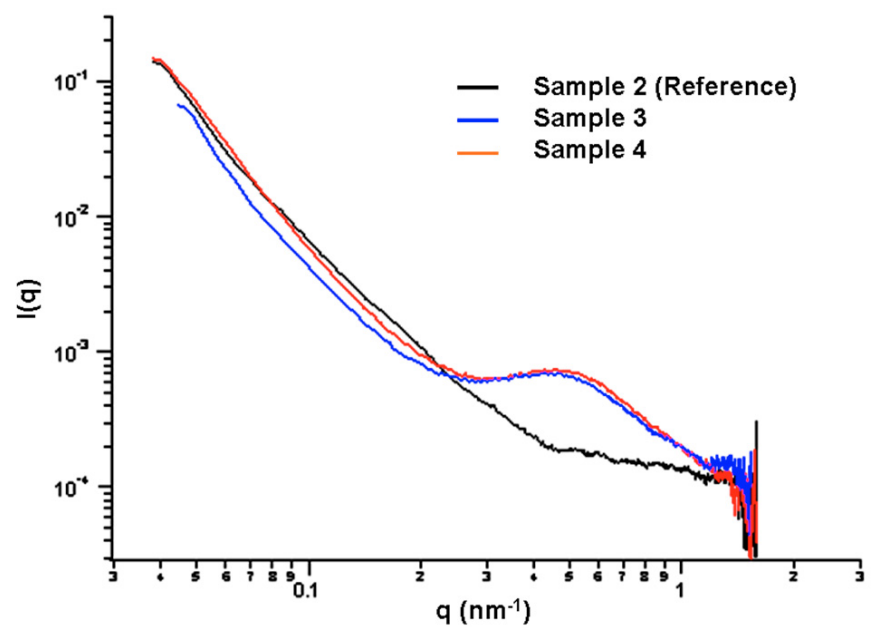

Fig. 7. (Color online) GI-SAXS patterns of implanted samples (3 and 4 ) and of a non-implanted sample (2).

plant. Moreover, GI-SAXS results look more reliable than TEM analyses for the observation of crystalline defects. As a matter of fact, TEM cross-sections reveal the disturbance of the electronic cloud created by the occurrence of crystalline defects within the whole TEM lamella. Although the TEM lamella thickness was accurately controlled, 3D effects arising from stacking several crystalline defects in the whole lamella thickness can affect the 
determination of crystalline defects size and density. GISAXS technique, which is only based on the scattering induced by crystalline defects, is only affected by the size and density of these defects. Accordingly GI-SAXS looks more sensitive to crystalline defects than TEM.

\section{X-ray metrology of nitrided silicon oxide gate dielectrics}

As MOS dimensions decrease, it becomes necessary to use ultra-thin gate dielectrics to reduce short-channel effects such as threshold voltage fluctuations and the degradation of the $I-V$ characteristics. Thermal silicon oxide $\left(\mathrm{SiO}_{2}\right)$ layers, which have been used since the beginning of MOS technology, can no longer be used when their thicknesses become too small. Electrical effects associated with hot carrier transport and boron diffusion through the thin silicon oxide film impact MOS transistor reliability by inducing threshold voltage instabilities, reducing in this way the transistor lifetime and altering the gate dielectric reliability.

To solve this problem, well-controlled insertion of nitrogen in ultra-thin $\mathrm{SiO}_{2}$ films has been developed. The MOS transistor performance enhancement induced by the introduction of nitrogen is mainly attributed to the high nitrogen concentration at the $\mathrm{SiON} / \mathrm{Si}$ interface. Thin nitrided $\mathrm{SiO}_{2}$ films, hereafter referenced as SiON films, exhibit very interesting properties: immunity against hot carriers and a good barrier to prevent boron diffusion. Nevertheless, the nitrogen concentration needs to be carefully mastered because if the level of nitrogen at the $\mathrm{SiON} / \mathrm{Si}$ interface is too high, it will degrade the MOS transconductance and create thermal instabilities of the MOS characteristics. From dedicated MOS investigation, the optimal nitrogen concentration at the $\mathrm{SiON} / \mathrm{Si}$ interface looks close to 1 to 2 at.\%. In parallel, the nitrogen profile inside the thin SiON film must be carefully controlled to ensure optimal MOS properties and reliability.

Thermal nitridation (RTN) of thermal $\mathrm{SiO}_{2}$ gate dielectrics consists in annealing the $\mathrm{SiO}_{2}$ film under a $\mathrm{NO}$ atmosphere at $900{ }^{\circ} \mathrm{C}$ during $30 \mathrm{~s}$. Plasma nitridation (DPN) of a $\mathrm{SiO}_{2}$ film is obtained using $\mathrm{N}_{2}$ plasma for 100 to $1000 \mathrm{~s}$ at room temperature, followed by a $10 \mathrm{~s}$ anneal under $\mathrm{O}_{2}$ partial pressure at $1000{ }^{\circ} \mathrm{C}$. The nitrogen profile of RTN and DPN films are rather different: RTN films exhibit a high $\mathrm{N}$ concentration at the $\mathrm{SiON} / \mathrm{Si}$ interface, while the DPN films present a diffusion-like N profile; the nitrogen concentration is higher at the top SiON surface and decreases down to the $\mathrm{SiON} / \mathrm{Si}$ interface [26].

Because the escape depth of photoelectrons excited by the X-ray beam is limited to $10 \mathrm{~nm}$, XPS is very well suited to monitor ultra-thin films like nitrided gate oxides $(\mathrm{SiON})$. Identification of chemical bonds in the film is easily achieved by an accurate measurement of the photoelectron binding energy which can be used, for instance, to differentiate silicon species among bulk $\mathrm{Si}, \mathrm{SiO}_{x}$ and $\mathrm{SiN}_{x}$ (Fig. 5).

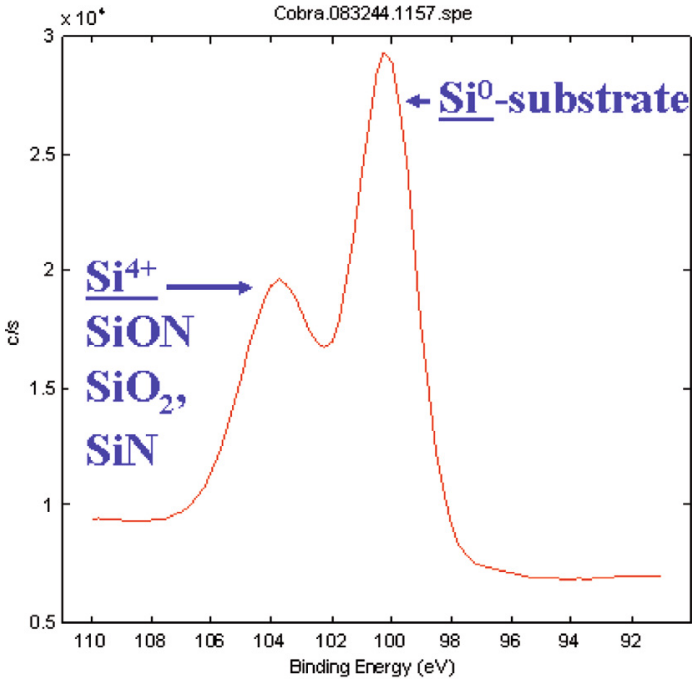

Fig. 8. (Color online) XPS $\mathrm{Si}-2 p^{3 / 2}$ spectrum of a very thin SiON film.

\subsection{Metrology of SiON film thickness using XPS}

The SiON film thickness is determined using the ratio between the peak intensity (area) attributed to $\mathrm{SiO}_{2}$ and SiON $\left(\mathrm{Si}^{4+}\right)$ chemical Si- $2 p$ bonds, and the peak intensity (area) characteristic of $\mathrm{Si}-\mathrm{Si}\left(\mathrm{Si}^{0}\right) \mathrm{Si}-2 p^{3 / 2}$ bonds, which exhibit binding energies close to $100 \mathrm{eV}$ (Fig. 8). By neglecting the contribution of interfacial oxides: $\mathrm{Si}^{1+}, \mathrm{Si}^{2+}$ and $\mathrm{Si}^{3+}$ ions, the intensity $I_{\mathrm{SiON}}$ of $\mathrm{Si}-2 p$ photoelectrons arising from the $\mathrm{Si}-\mathrm{O}$ and $\mathrm{Si}-\mathrm{N}$ chemical bonds present in a $\mathrm{SiON}$ film with a thickness $d$, can be expressed as [27]:

$$
I_{\mathrm{SiON}} \approx n_{\mathrm{SiON}} \sigma_{\mathrm{SiON}} \int_{0}^{d} \exp \left(-\frac{z}{l_{\mathrm{SiON}}}\right) d z
$$

and, consequently:

$$
I_{\mathrm{SiON}}=n_{\mathrm{SiON}} \sigma_{\mathrm{SiON}} l_{\mathrm{SiON}}\left[1-\exp \left(-\frac{d}{l_{\mathrm{SiON}}}\right)\right] .
$$

By analogy, the intensity of Si- $2 p$ photoelectrons arising from $\mathrm{Si}-\mathrm{Si}$ chemical bonds in the same $\mathrm{SiON}$ film is:

$$
\begin{aligned}
& I_{\mathrm{Si}} \approx n_{\mathrm{Si}} \sigma_{\mathrm{Si}} \exp \left(-\frac{d}{l_{\mathrm{SiON}}}\right) \int_{0}^{\infty} \exp \left(-\frac{z^{\prime}}{l_{\mathrm{Si}}}\right) d z^{\prime} \\
& I_{\mathrm{Si}}=n_{\mathrm{Si}} \sigma_{\mathrm{Si}} l_{\mathrm{Si}} \exp \left(-\frac{d}{l_{\mathrm{SiON}}}\right),
\end{aligned}
$$

in which $\sigma_{\mathrm{Si}}$ and $\sigma_{\mathrm{SiON}}$ are the photo-ionisation crosssection, $l_{\mathrm{Si}}$ and $l_{\mathrm{SiON}}$ the inelastic mean free path of $\mathrm{Si}-2 p$ photoelectrons, and $n_{\mathrm{Si}}$ and $n_{\mathrm{SiON}}$ the silicon atomic density in $\mathrm{Si}$ and $\mathrm{SiON}$.

Combining equations (8) and (10):

$$
\frac{I_{\mathrm{SiON}}}{I_{\mathrm{Si}}}=\frac{I_{\infty}}{I_{0}}\left[\exp \left(\frac{d}{l_{\mathrm{SiON}}}\right)-1\right]
$$


where $I_{\infty}=n_{\mathrm{SiON}} \sigma_{\mathrm{SiON}} l_{\mathrm{SiON}}$ and $I_{0}=n_{\mathrm{Si}} \sigma_{\mathrm{Si}} l_{\mathrm{Si}}$ correspond to the $\mathrm{Si}-2 p$ photoelectron intensity emitted by an infinitely thick SiON film and by the Si substrate, respectively.

The thickness $d$ can then be expressed as:

$$
d=l_{\mathrm{SiON}} \ln \left[\left(\frac{I_{\mathrm{SiON}}}{I_{\mathrm{Si}}} \frac{I_{O}}{I_{\infty}}\right)+1\right]
$$

The Si- $2 p$ photoelectron intensities (area) $I_{\mathrm{SiON}}$ and $I_{\mathrm{Si}}$ are determined from the experimental XPS spectra of SiON films. The ratio $I_{0} / I_{\infty}$ has been empirically determined and is equal to 0.82 [24]. The inelastic mean free path of $\mathrm{Si}-2 p$ photoelectrons in the SiON films depends on the photoelectron kinetic energy and on the chemical composition of the SiON films. In this study we considered that this value is independent of the nitrogen content in the $\mathrm{SiON}$ films and is equal to $l_{\mathrm{SiON}}=l_{\mathrm{SiO}_{2}}=$ $2.964 \mathrm{~nm}$ [28].

The SiON film thickness monitored using XPS metrology agrees quite well with thickness values measured using conventional spectroscopic ellipsometry (SE) (Fig. 9a), whatever the $\mathrm{N}$ content, the nitridation method or the SiON film thickness. Nevertheless, the SiON film thicknesses monitored by XPS are always slightly higher than the ones measured using SE. This discrepancy between the thickness values determined using XPS and SE tends to increase with an increase in the $\mathrm{N}$ concentration of SiON films (Fig. 9b). Thus, the assumption about the independence of the photoelectron inelastic mean free path $l_{\mathrm{SiON}}$ relative to the $\mathrm{N}$ content in $\mathrm{SiON}$ is probably not strictly valid.

\subsection{Metrology of $\mathrm{N}$ dose and profile in SiON films using XPS}

One of the main advantages of the XPS technique for monitoring ultra-thin SiON films is that one can determine the $\mathrm{N}$ dose independently of the SiON film thickness and of the presence of contaminants, like carbon molecules adsorbed on the sample surface, which alter the accuracy of thickness measurements when using ellipsometry.

The method we used for determining the $\mathrm{N}$ dose is similar to the one we used for characterizing the SiON film thickness. Such a method must obviously take into account the nitrogen depth profile in the SiON film.

The intensity of $\mathrm{N}-1 s$ photoelectrons emitted by the SiON film around $400 \mathrm{eV}$ (Fig. 10) can be expressed as:

$$
\begin{aligned}
I(\mathrm{~N}) \approx & \int_{0}^{d} \sigma_{\mathrm{SiON}}(\mathrm{N}-1 s) c(\mathrm{~N}, z) \\
& \times \exp \left(-\int_{O}^{z} \frac{d z}{l_{\mathrm{SiON}}(z, E) \sin \theta}\right) d z
\end{aligned}
$$

where $\sigma_{\mathrm{SiON}}(\mathrm{N}-1 s)$ is the photo-ionisation cross-section of the $\mathrm{N}-1 s$ core level, $c(\mathrm{~N}, z)$ is the $\mathrm{N}$ depth profile at a depth $z$ in the $\operatorname{SiON}$ film, $l_{\mathrm{SiON}}(z, E)$ is the escape depth

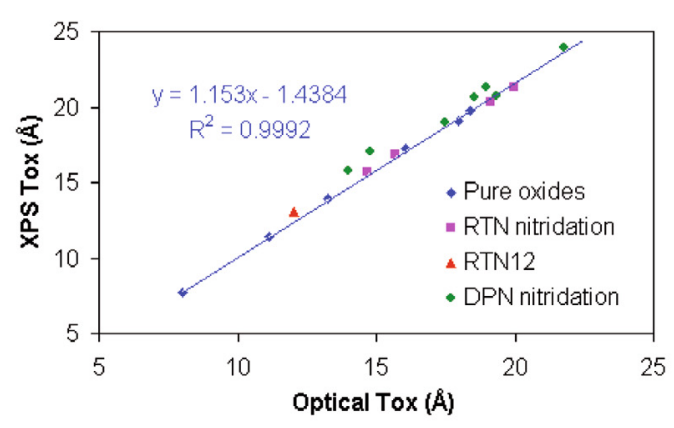

a) Comparison between the SiON film thicknesses monitored using XPS and SE

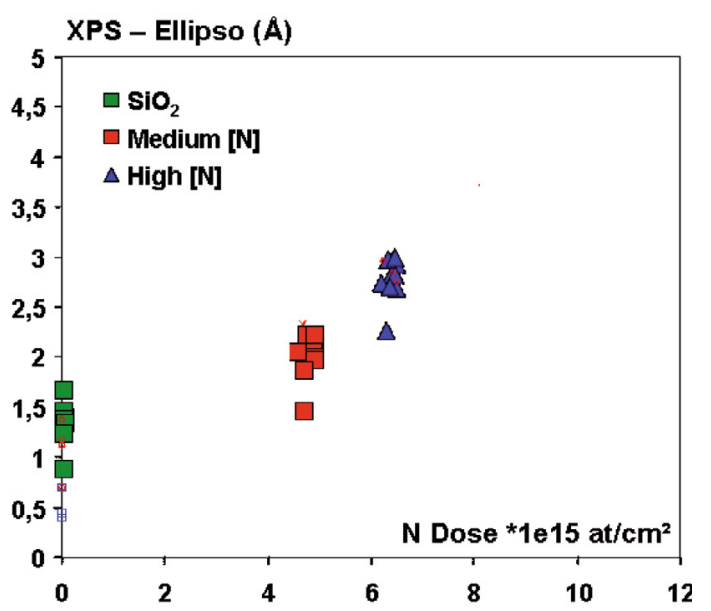

b) Evolution of the difference between $\mathrm{SiON}$ film thicknesses measured using XPS and SE as a function of $\mathrm{N}$ dose

Fig. 9. (Color online) Correlation between the SiON film thicknesses monitored using XPS and SE.

of photoelectrons with a kinetic energy $E$ at a depth $z$, and, $\theta$ is the detection angle or angle between the surface normal and the detector position.

By analogy, the intensity of Si- $2 p$ and O- $1 s$ photoelectrons emitted by the SiON film can be expressed as:

$$
\begin{aligned}
I(\mathrm{Si})= & \sigma_{\mathrm{SiON}}(\mathrm{Si}-2 p) c(\mathrm{Si}) l_{\mathrm{SiON}}(\mathrm{Si}, E) \\
& \times \sin \theta \exp \left(-\int_{0}^{d} \frac{d z}{l_{\mathrm{SiON}}(z, E) \sin \theta}\right) \\
I(\mathrm{O}) \approx & \int_{0}^{d} \sigma_{\mathrm{SiON}}(\mathrm{O}-1 s) c(\mathrm{O}, z) \\
& \times \exp \left(-\int_{0}^{z} \frac{d z}{l_{\mathrm{SiON}}(z, E) \sin \theta}\right) d z .
\end{aligned}
$$

Because it is obvious that the accurate determination of the $\mathrm{N}$ dose in thin $\mathrm{SiON}$ films requires the reliable determination of the $\mathrm{N}$ profile in SiON films, we investigated two different techniques for assessing the $\mathrm{N}$ profiles in various SiON films: 


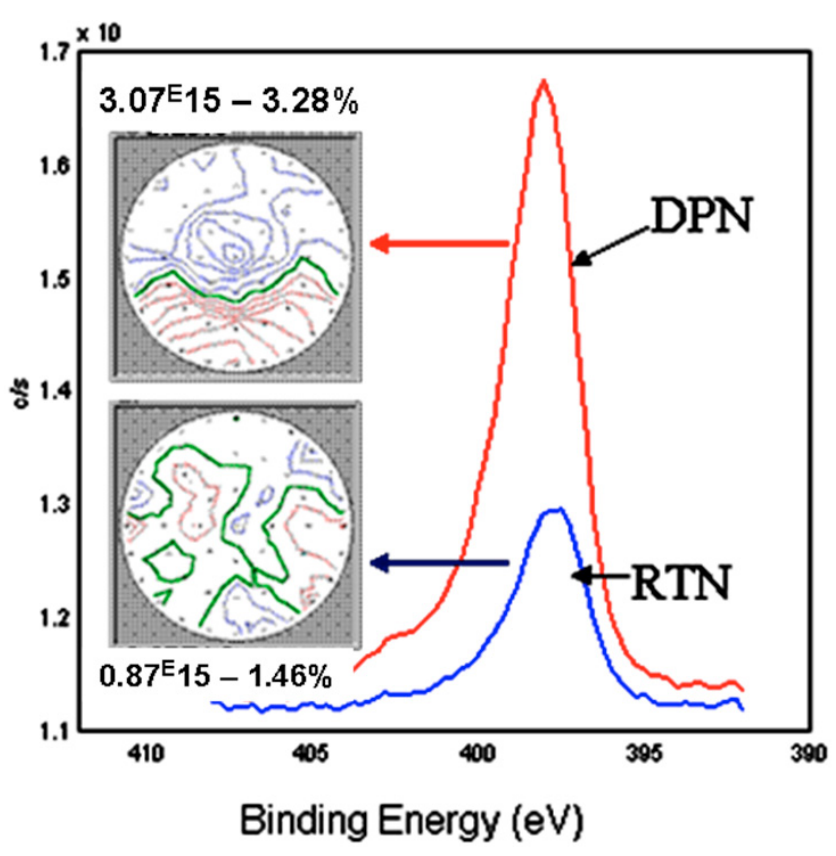

Fig. 10. (Color online) XPS N-1s spectra of two thin RTN and DPN SiON films. Inset: $\mathrm{N}$ dose mapping across $300 \mathrm{~mm}$ wafers.

- photoelectron energy distribution,

- partial etching of SiON films.

Tougaard [29] developed a model for quantitative analyses of surfaces using XPS, which takes into account a heterogeneous distribution of elements in very thin layers. This model is based on the inelastic scattering of photoelectrons. Inelastic scattering of photoelectrons from a heterogeneous element depth distribution can strongly lower both the XPS peak intensity and affect the kinetic energy of the considered element. Furthermore, the background signal close to the XPS peak of this element can provide valuable information about the depth distribution of this element.

We applied Tougaard's model for RTN and DPN SiON films. Unambiguously, the XPS background signal of N-1s photoelectron emitted by thin SiON films allows the discrimination between RTN and DPN films. But, in spite of numerous efforts, we were unable to reliably and accurately extract the $\mathrm{N}$ concentration profiles from XPS background signal. Especially, the $\mathrm{N}$ concentration at the $\mathrm{SiON} / \mathrm{Si}$ interface, which is so critical for the performances and reliability of CMOS transistors could be determined without a very large uncertainty.

In order to determine the $\mathrm{N}$ depth distribution in RTN and DPN films, the SiON films were gradually etched in dilute HF. After each partial etch, each one removing around $0.1 \mathrm{~nm}$, the $\mathrm{N}$ dose was calculated assuming a homogeneous $\mathrm{N}$ depth distribution. If we consider that the nitrogen, oxygen and silicon are uniformly distributed in the SiON film, integration of equation (13)

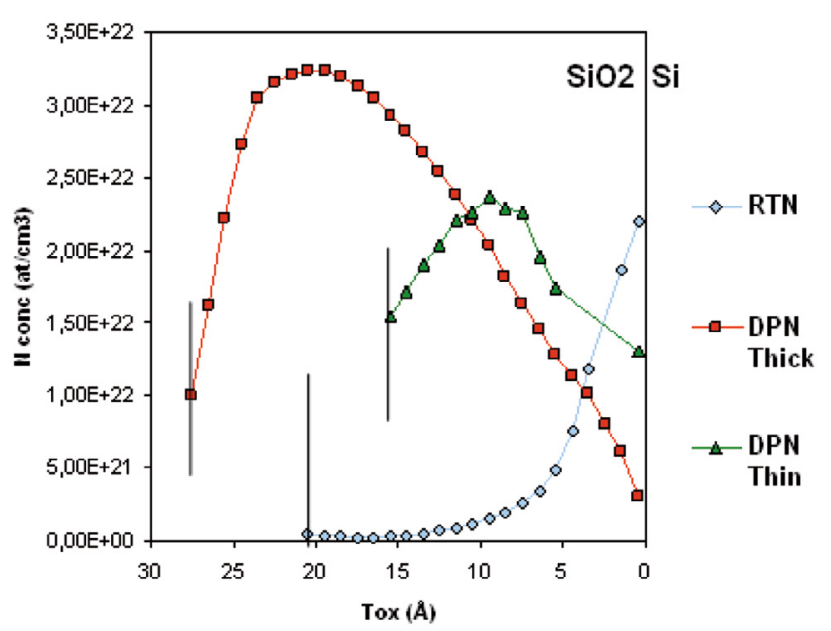

Fig. 11. (Color online) Nitrogen depth distribution in RTN and DPN films. The depth distribution has been determined using partial etching of the SiON films.

leads to the $\mathrm{N}$ dose:

$$
\begin{aligned}
& N_{\text {dose }}\left(\text { at.cm }^{-2}\right)=\int_{0}^{d} c(\mathrm{~N}, z) d z \\
& =\left[\left(\frac{I(\mathrm{~N})}{A S F_{\mathrm{N}}}\right) /\left(\frac{I(\mathrm{Si})}{A S F_{\mathrm{Si}}}\right)\right] \rho_{\mathrm{SiON}} d,
\end{aligned}
$$

where $\mathrm{ASF}_{\mathrm{N}}$ and $\mathrm{ASF}_{\mathrm{Si}}$ are the atomic sensibility factors, respectively equal to 0.477 and $0.339\left(\mathrm{ASF}_{\mathrm{O}}=0.711\right)$ and $\rho_{\mathrm{SiON}}$ is the atomic density of the SiON with a thickness $d$. This protocol was repeated after each partial etch of the thin SiON films, and the $\mathrm{N}$ dose was corrected accordingly.

Using this protocol we determined the $\mathrm{N}$ depth profile $c(\mathrm{~N}, z)$ in SiON films, assuming the $\mathrm{N}$ concentration at the $\mathrm{SiON} / \mathrm{Si}$ interface. This concentration has been estimated for DPN and RTN films and is respectively equal to (Fig. 11):

$$
\begin{aligned}
& \mathrm{N}=2.5 \pm 0.1 \times 10^{22} \text { at.cm }{ }^{-3} \text { for RTN; } \\
& \mathrm{N}=2 \times 10^{22} \text { at.cm }^{-3} \text { for DPN. }
\end{aligned}
$$

$\mathrm{N}$ depth distribution data from the various SiON films were introduced as input data to correct the dose measurement assuming a uniform depth profile (Eq. (16)) and determining the effective $\mathrm{N}$ dose in these films.

The $\mathrm{N}$ depth distributions determined by XPS agree quite well with the $\mathrm{N}$ depth profiles measured using ToFSIMS [26] but do not agree with the $\mathrm{N}$ depth distributions measured by Hattori et al. [30] using Angle-Resolved XPS. Although the process conditions for preparing the SiON films look very similar to the ones we used, the $\mathrm{N}$ depth distribution of all RTN films was identical while the $\mathrm{N}$ depth profile of the DPN films was inverted compared to the $\mathrm{N}$ profile we determined using XPS (Fig. 11).

The high potential of XPS as a metrology tool for monitoring the thickness and $\mathrm{N}$ dose of SiON gate dielectrics relies on its ability to forecast the electrical properties of MOS transistors. The $\mathrm{N}$ dose distribution can be 


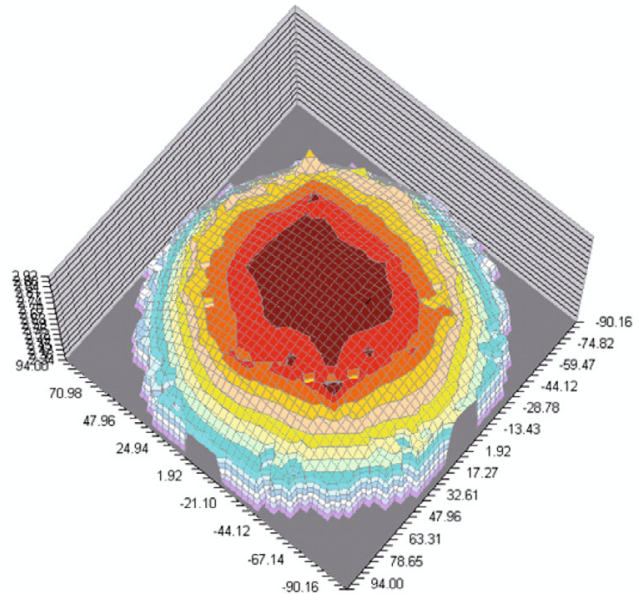

a) $\mathrm{N}$ dose distribution of a DPN film across a $300 \mathrm{~mm}$ wafer

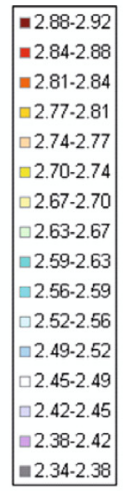

b) Threshold voltage mapping of PMOS transistors $\left(10 \times 10 \mu \mathrm{m}^{2}\right.$, 56 dice) with DPN gate dielectrics

[31]

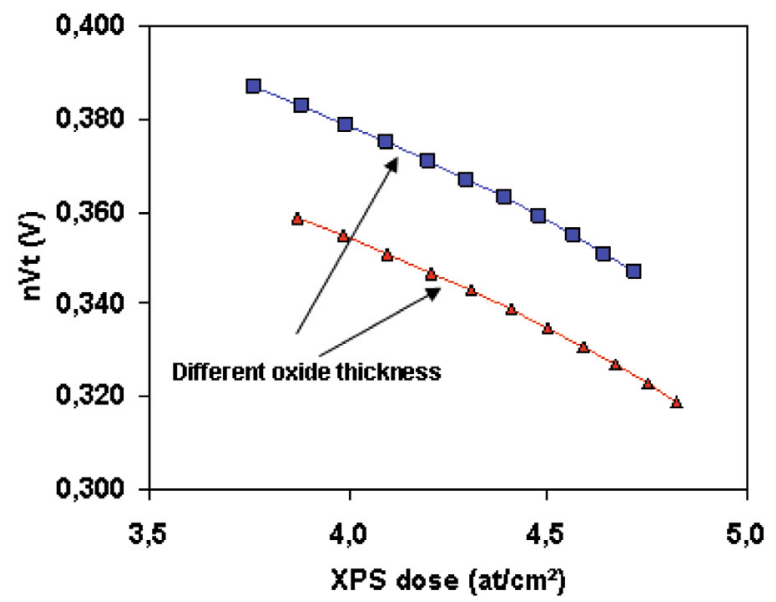

c) Evolution of PMOS threshold voltage as a function of the N dose determined using XPS

Fig. 12. (Color online) Correlation between the $\mathrm{N}$ dose monitored using XPS and electrical properties of PMOS transistors.

directly coupled to the threshold voltages of MOS transistors (Figs. 12a and 12b) [31]. Moreover, the combined monitoring of the SiON film thickness and $\mathrm{N}$ dose using XPS can be used to determine the equivalent gate oxide thickness (EOT), the capacitance equivalent gate thickness (CET) [32] (which takes into account the poly-Si gate depletion [32]) and the MOS threshold voltage (Fig. 12c). The EOT, CET and threshold voltages of NMOS and PMOS transistors determined and calculated from the XPS monitoring results perfectly agree with the values measured during the electrical sorting.

\section{X-ray metrology of NiSi thin films}

NiSi films are used to reduce the overall contact resistance between the silicon part of MOS transistors (gate, source and drain) and the $\mathrm{Cu}$ interconnects. NiSi exhibits several advantages compared to the commonly used silicides
$\mathrm{TiSi}_{2}$ and $\mathrm{CoSi}_{2}$ : (i) NiSi formation occurs at low temperatures, around $400{ }^{\circ} \mathrm{C}$; (ii) NiSi thermal stability, in particular when NiSi is doped with platinum; (iii) formation of abrupt interfaces with $\mathrm{Si}$; (iv) low Si consumption and (v) very low linewidth dependence of its resistivity.

The integration of $\mathrm{NiSi}$ in the CMOS process is achieved using 5 successive process steps (Fig. 13): (i) proper cleaning of the silicon surface [33]; (ii) physical vapour deposition (PVD) of a thin Pt doped Ni film followed by deposition of a PVD TiN capping layer; (iii) rapid thermal annealing (RTA) to form $\mathrm{Ni}_{2} \mathrm{Si}$; (iv) selective etch of the TiN capping layer and (v) RTA of the $\mathrm{Ni}_{2} \mathrm{Si}$ film to form $\mathrm{NiSi}$.

If the last RTA is not perfectly mastered, NiSi films tend to transform into the higher resistivity phase, $\mathrm{NiSi}_{2}$ (Tab. 1). Due to the high solubility of $\mathrm{Pt}$ in NiSi and its very low solubility in $\mathrm{NiSi}_{2}, \mathrm{Pt}$ doping of $\mathrm{NiSi}$ is very useful in reducing or preventing the transformation $\mathrm{NiSi}=>\mathrm{NiSi}_{2}$. Since this transformation consumes a lot 


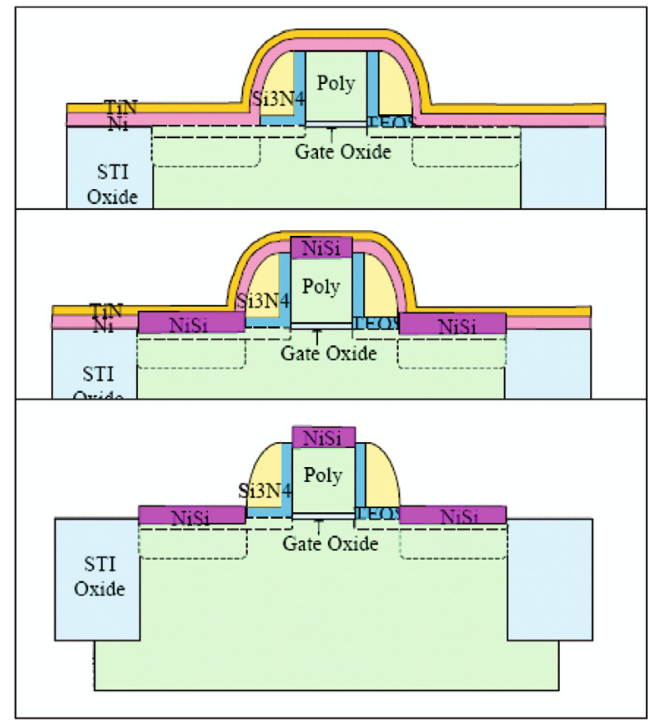

Fig. 13. (Color online) Integration of $\mathrm{NiSi}$ in a $65 \mathrm{~nm}$ CMOS process.

Table 1. Properties of $\mathrm{Ni}$ and of the main nickel silicide phases.

\begin{tabular}{cccc}
\hline & $\begin{array}{c}\text { Electrical } \\
\text { resistivity } \\
(\mu \Omega \mathrm{cm})\end{array}$ & $\begin{array}{c}\text { Mass } \\
\text { density } \\
\left(\mathrm{g} \mathrm{cm}^{-3}\right)\end{array}$ & $\begin{array}{c}\text { Electron } \\
\text { density } \\
\left(\mathrm{nm}^{-3}\right)\end{array}$ \\
\hline $\mathrm{Ni}$ & 7 & 8.91 & 2500 \\
$\mathrm{Ni}_{2} \mathrm{Si}$ & 27 & 7.51 & 2140 \\
$\mathrm{NiSi}$ & 17 & 5.97 & 1750 \\
$\mathrm{NiSi}_{2}$ & 40 & 4.8 & 1410 \\
\hline
\end{tabular}

of silicon, $\mathrm{NiSi}_{2}$ formation usually induces junction leakage, which can be detrimental for the MOS properties.

NiSi films can exhibit crystalline epitaxial relationships with adjacent silicon areas, leading to the formation of large crystalline facets called axiotaxy [34]. Coupled to the physical phenomena leading to axiotaxy, NiSi films tend to agglomerate when the annealing temperature is too high. Pt doping of $\mathrm{NiSi}$ is also useful to reduce $\mathrm{NiSi}$ agglomeration since it tends to decrease the importance of axiotaxy [35].

Monitoring the NiSi formation from $\mathrm{Ni}$ deposition through the thermal anneals is delicate and extremely critical for the integration of nickel silicide in $65 \mathrm{~nm}$ and beyond MOS process.

Since the contrast between the electron densities of the various nickel silicide phases is very large (Tab. 1), $\mathrm{XRR}$ is very well suited and, probably, the fastest available metrology technique to monitor the formation kinetics, the thickness and the thermal stability of NiSi films. Figure 14 shows XRR patterns of a $10 \mathrm{~nm}$ deposited Ni film with a TiN capping layer of $10 \mathrm{~nm}$ annealed at $330{ }^{\circ} \mathrm{C}$ (a), $370{ }^{\circ} \mathrm{C}(\mathrm{b})$, and $450{ }^{\circ} \mathrm{C}$ (c). The XRR experiment was run after selective etch of the TiN cap and the unreacted $\mathrm{Ni}$ with an acquisition time of $30 \mathrm{~s}$. At low temperatures (Fig. 14a), the $\mathrm{Ni}_{2} \mathrm{Si}$ phase is present with a density of $\sim 7.9 \mathrm{~g} / \mathrm{cm}^{3}$, which is slightly higher than the $7.4 \mathrm{~g} / \mathrm{cm}^{3}$

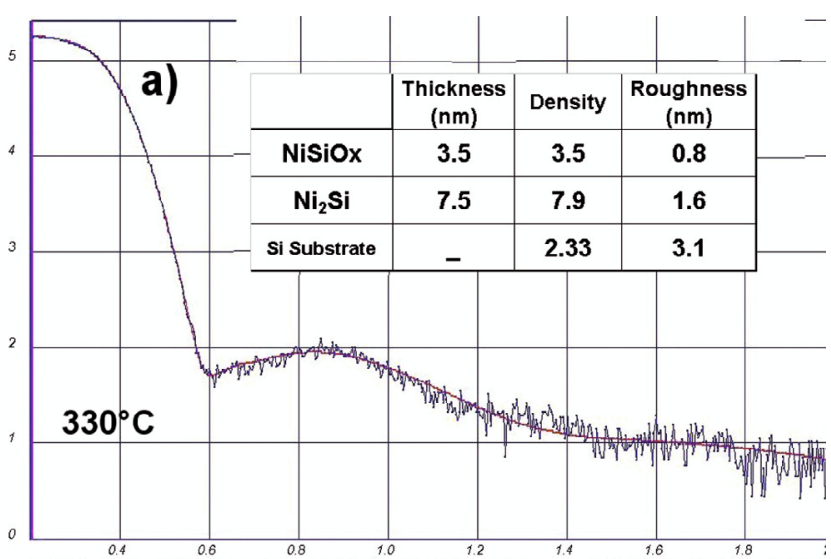

a) annealed at $330^{\circ} \mathrm{C}$

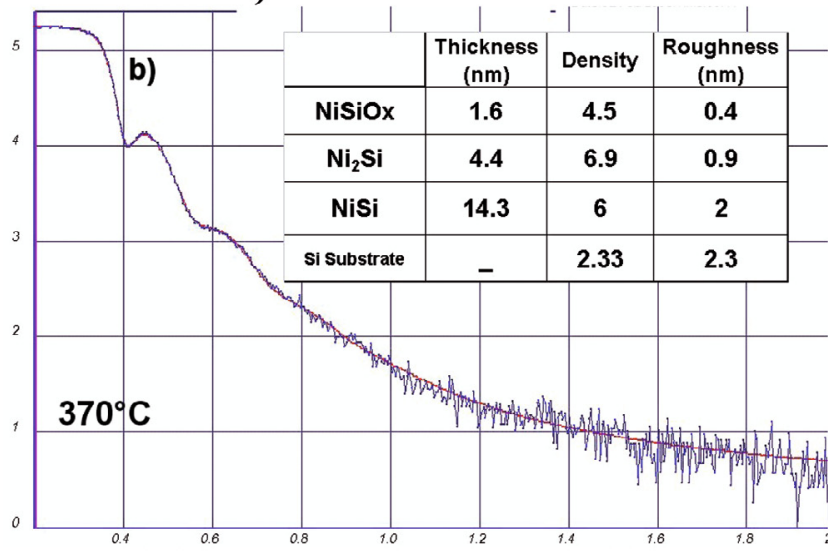

b) annealed at $370^{\circ} \mathrm{C}$

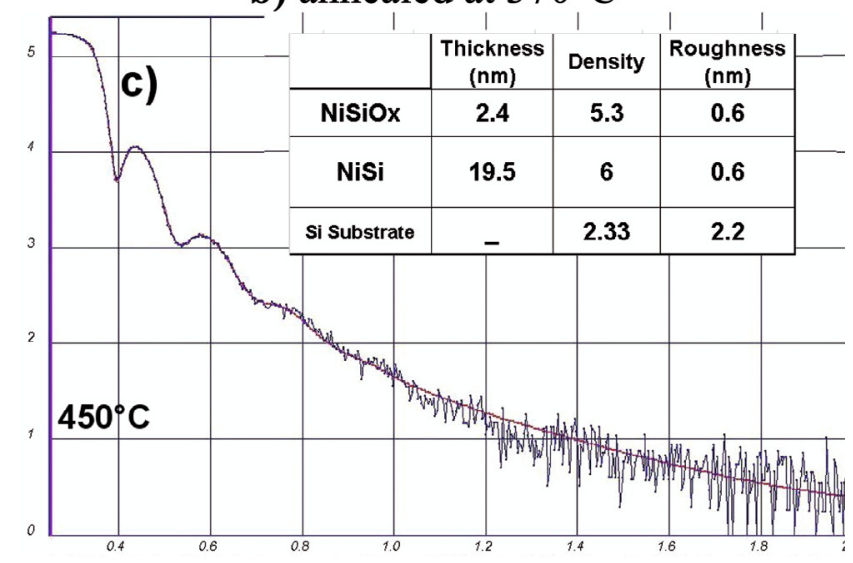

c) annealed at $450^{\circ} \mathrm{C}$

Fig. 14. (Color online) Evolution of XRR patterns of a $10 \mathrm{~nm}$ thick Ni film annealed at (a) $330{ }^{\circ} \mathrm{C}$, (b) $370{ }^{\circ} \mathrm{C}$ and (c) $450{ }^{\circ} \mathrm{C}$.

value reported in the JCPDS file. This slightly higher $\mathrm{Ni}_{2} \mathrm{Si}$ density value can be explained by an incomplete phase transformation due to the very low thermal budget. At intermediate temperatures, typically between $350{ }^{\circ} \mathrm{C}$ and $450{ }^{\circ} \mathrm{C}$ (Fig. 14b), the model describes a stack having a bottom NiSi layer with a measured density $\sim 6 \mathrm{~g} / \mathrm{cm}^{3}$ (in good agreement with JCPDS file information for NiSi) and a top $\mathrm{Ni}_{2} \mathrm{Si}$ layer with a temperature-dependent density. When these two phases co-exist, the total thickness of the silicide film can be calculated as the sum of the NiSi 


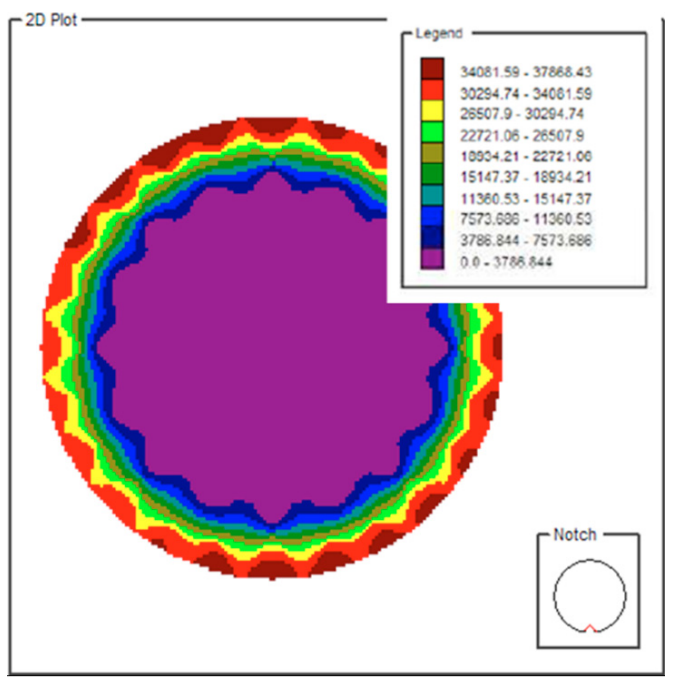

Fig. 15. (Color online) 49 points contour plot of NiSi (002) diffraction peak intensity across a $300 \mathrm{~mm}$ wafer-acquisition: $30 \mathrm{~s} /\left(50 \times 50 \mu \mathrm{m}^{2}\right.$ site $)$.

thickness and the "density-weighted" $\mathrm{Ni}_{2} \mathrm{Si}$ thickness, as given by the XRR model. At $450{ }^{\circ} \mathrm{C}$ (Fig. 14c), the nickel silicide film is completely transformed into NiSi, and the XRR model reveals a thick NiSi layer and a thin $(2.4 \mathrm{~nm})$ top oxidized layer $\left(d \sim 5.3 \mathrm{~g} / \mathrm{cm}^{3}\right)$. This study provided an accurate and reliable measurement of the NiSi film thickness as a function of annealing temperature, and showed a good correlation between the thickness and the electrical properties of the silicide [36].

Due to the high number of stable crystalline phases in the Ni-Si phase diagram: $\mathrm{Ni}_{3} \mathrm{Si}, \mathrm{N}_{31} \mathrm{Si}_{12}, \mathrm{Ni}_{2} \mathrm{Si}_{,} \mathrm{Ni}_{3} \mathrm{Si}_{2}$, $\mathrm{NiSi}$ and $\mathrm{NiSi}_{2}, \mathrm{XRD}$ has been widely used to understand the formation and thermal stability of NiSi films $[37,38]$.

We also used XRD to control the formation and thermal stability of NiSi, and, especially, the uniformity of the $\mathrm{NiSi}$ formation across a $300 \mathrm{~mm}$ wafer. As a matter of fact, since the transformation of $\mathrm{Ni}_{2} \mathrm{Si}$ in $\mathrm{NiSi}$ is very sensitive to temperature fluctuations, this transformation must be monitored on the whole Si wafer. XRD is the appropriate metrology technique for this process control. It allows the discrimination between the wafer areas where NiSi is already formed and the wafer areas where this transformation is not complete or has not yet begun.

As an example, Figure 15 presents the mapping of the NiSi (002) diffraction peak intensity across a $300 \mathrm{~mm}$ wafer. The NiSi (002) intensity is very large at the wafer edge, while it is almost zero at the wafer centre. This XRD mapping indicates that the $\mathrm{Ni}_{2} \mathrm{Si}=>\mathrm{NiSi}$ change starts at the wafer edge. This monitoring result can be used to adjust RTA experimental parameters in order to achieve homogenous transformation across the whole $300 \mathrm{~mm}$ wafer.

As explained above, doping the Ni with Pt significantly enhances NiSi thermal stability and reduces NiSi axiotaxy. Consequently, monitoring the Pt content in NiSi films becomes critical when integrating Pt doped NiSi films in the CMOS process. This monitoring was successfully achieved using $\mu$-spot XRF (Fig. 16).

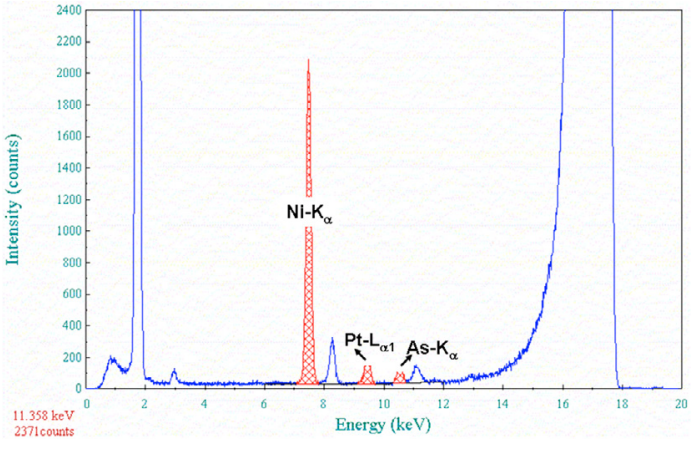

Fig. 16. (Color online) XRF spectrum of a Pt doped NiSi film over $n^{+}$(As)-Si active zones. Excitation: Mo-K $\mathrm{K}_{\alpha}$.

XRF spectra of Pt doped NiSi films are typically obtained using an acquisition time of $20 \mathrm{~s}$ per $70 \times 70 \mu \mathrm{m}^{2}$ site. The high energy discrepancies between XRF peaks of Pt- $\mathrm{L}_{\alpha 1}, \mathrm{Ni}-\mathrm{K}_{\alpha}$ and the $\mathrm{n}$-doping elements $\left(\mathrm{As}-\mathrm{K}_{\alpha}\right)$ (Fig. 16) make it possible to accurately determine the concentration of each element, once a precise and careful calibration of the fluorescence of the constitutive elements has been carried out.

On product wafers, XRF could also be used to monitor NiSi film thickness based on the fluorescence intensity of $\mathrm{Ni}$ species. In this case, the Ni fluorescence intensity should be calibrated using XRR, which determines the mass-density and thickness of $\mathrm{NiSi}_{x}$ films. The relationship between the $\mathrm{Ni}$ XRF intensity and the $\mathrm{NiSi}_{x}$ film thickness is not totally linear, even when we take into account the various mass-densities of $\mathrm{NiSi}_{x}$ crystalline phases inside the calibration protocol. Further experiments highlight that the Ni XRF intensity is only correlated to the initial $\mathrm{Ni}$ film thickness and does not change during the $\mathrm{NiSi}_{x}$ film formation [39].

\section{X-ray metrology of low- $\kappa$ dielectrics}

The increase of interconnect delay when scaling down the size of CMOS transistors seriously impacts integrated circuit performance. In order to overcome these issues, $\mathrm{Cu}$ interconnects and low- $\kappa$ materials have been introduced starting with the $120 \mathrm{~nm}$ MOS generation, to lower the overall resistance and capacitance of metal interconnects.

The first approach used to lower the dielectric constant of the insulating materials was to change the chemical composition of chemical vapor deposited (CVD) $\mathrm{SiO}_{2}$ films. Part of the $\mathrm{O}$ atoms was replaced by $\mathrm{F}$ atoms, and finally by $\mathrm{C}$ atoms (SiOC layers). In order to further reduce the dielectric permittivity, porosity was introduced in the insulating layers.

The introduction of porosity in the insulating materials does not only affect their electrical properties, but considerably alters their thermo-mechanical properties (Young modulus, hardness and thermal conductivity). Moreover, whereas the dielectric constant of low- $\kappa$ materials almost linearly decreases with the porosity, their thermomechanical properties decrease more rapidly [40]. 
Thus, the integration of porous low- $\kappa$ materials in the CMOS process is delicate and becomes more complicated when the porosity increases. Various original integration processes have been developed for a convenient and efficient integration of the porous low- $\kappa$ materials.

Nevertheless, porous low- $\kappa$ materials are highly sensitive to: (i) plasma discharges and cleaning/stripping, which can modify their chemical composition and their dielectric constant; (ii) the pore sealing process, which aims to close the pores before the deposition of $\mathrm{Cu}$ diffusion barrier films ( $\mathrm{Ta} / \mathrm{TaN}$ bilayer) on the low- $\kappa$ sidewalls; (iii) the chemical and mechanical polishing (CMP) process and the further post-CMP cleaning. Because their mechanical properties are very weak, low- $\kappa$ layers can be highly damaged during CMP: the post-CMP cleaning solution can diffuse inside the pores and impact the electrical properties of the low- $\kappa$ layers.

In order to control the manufacturing processes related to porous low- $\kappa$ layers, in-line monitoring must be used to survey the low- $\kappa$ film thickness, its overall porosity, the average pore size and the pore size distribution.

It has been shown that non-destructive X-ray techniques are powerful when characterizing low- $\kappa$ film density and thickness. Additionally, XRR and GI-SAXS have been used to measure the porosity and average pore size of low- $\kappa$ films $[41,42]$. We combined XRR and GI-SAXS to control the UV-curing, pore sealing and CMP processes involved in the manufacturing of $65 \mathrm{~nm}$ microelectronic devices [43].

The porous low- $\kappa$ layers were deposited using the plasma enhanced chemical vapour deposition (PECVD) technique with an organo-silicate precursor to create a $\mathrm{SiOCH}$ skeleton and an organic precursor called porogen. During the PECVD deposition, organic porogen inclusions enter the $\mathrm{SiOCH}$ matrix. UV-curing is performed around $350{ }^{\circ} \mathrm{C}$ to remove the porogen from the $\mathrm{SiOCH}$ matrix in order to create the pores. Pore sealing of the low- $\kappa$ sidewalls is carried out after etching of the Damascene patterns, using a plasma treatment.

$\mathrm{XRR}$ is a very convenient and fast metrology technique to control the porogen removal as well as the pore sealing process, since it is very sensitive to changes in the mass/electron density that occur during these two processes. As an example, Figure 17 shows XRR patterns (measured with an acquisition time of $20 \mathrm{~s}$ per site) of a pore sealed low- $\kappa$ film. It shows the mass-density change induced by the plasma treatment of the top low- $\kappa$ surface: while the mass-density of the bulk low- $\kappa$ film is $1.18 \mathrm{~g} \mathrm{~cm}^{-3}$, the measured pore sealed layer mass-density is $1.87 \mathrm{~g} \mathrm{~cm}^{-3}$.

The overall porosity $P$ of the low- $\kappa$ layer can be deduced from the mass-density $\rho$ of the low- $\kappa$ layer, using the following equation:

$$
\rho=\rho_{\text {wall }}(1-P)
$$

once the skeleton density $\rho_{\text {wall }}$ has been precisely determined.

According to the data provided by NIST researchers following the metrology of various low- $\kappa$ films, the electron density of low- $\kappa$ films can be directly correlated to

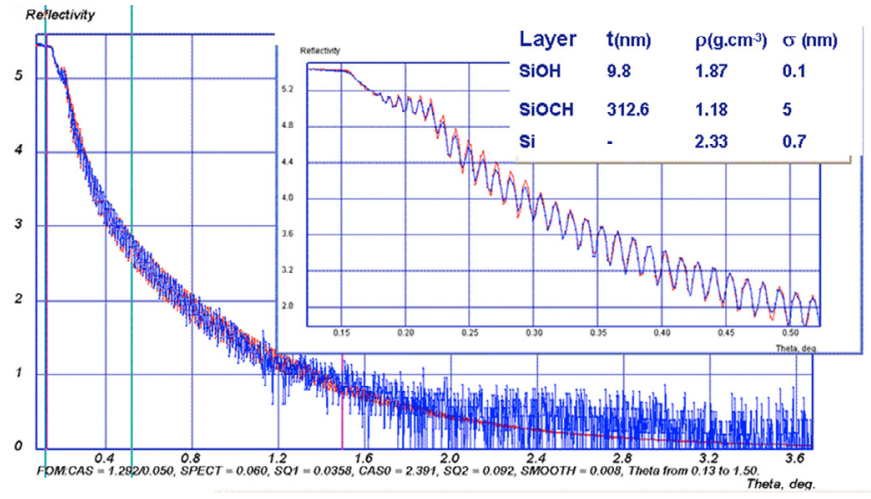

Fig. 17. (Color online) XRR pattern of a pore sealed $310 \mathrm{~nm}$ thick low- $\kappa$ layer. Inset: magnification of this XRR pattern from 0.13 to $0.5^{\circ}$ between the light-blue lines of the main figure.

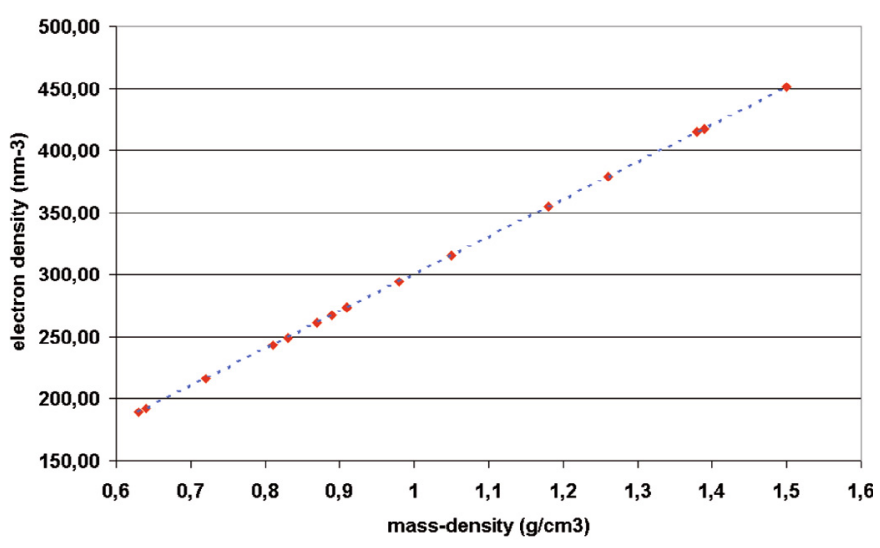

Fig. 18. (Color online) Evolution of the mass-density as a function of the electron density for various low- $\kappa$ films. Calculated from data [41-43].

their mass-density whatever their chemical composition and whatever the method used for deposition: PECVD or spin coating (Fig. 18) [44-46]. This suggests that any electron density changes detected and quantified by the XRR measurement of low- $\kappa$ films indicate a change in the mass-density, and consequently an evolution of the overall porosity of the low- $\kappa$ film.

We determined the skeleton density of the low- $\kappa$ film, using XRR, to be equal to $1.69 \mathrm{~g} \mathrm{~cm}^{-3}$. Consequently, the overall porosity of the low- $\kappa$ film presented on Figure 17 must be around $32 \%$.

The agreement between the overall porosity values obtained with XRR and with ellipsometric porosimetry (EP) [47] is good, even if the porosity values measured by XRR are generally slightly higher than the ones measured by EP (Fig. 19 and Tab. 2).

The XRR metrology system designed to measure thin film thicknesses was evaluated by measuring a $330 \mathrm{~nm}$ thick low- $\kappa$ film and comparing the results with those obtained using the well-known and often employed spectroscopic ellipsometry (SE) technique. The discrimination ratio (Dr) refers to the capability of a measurement tool to detect and adequately measure small changes in a specific characteristic. The $\% \mathrm{P} / \mathrm{T}$ value is the percent Precision to 


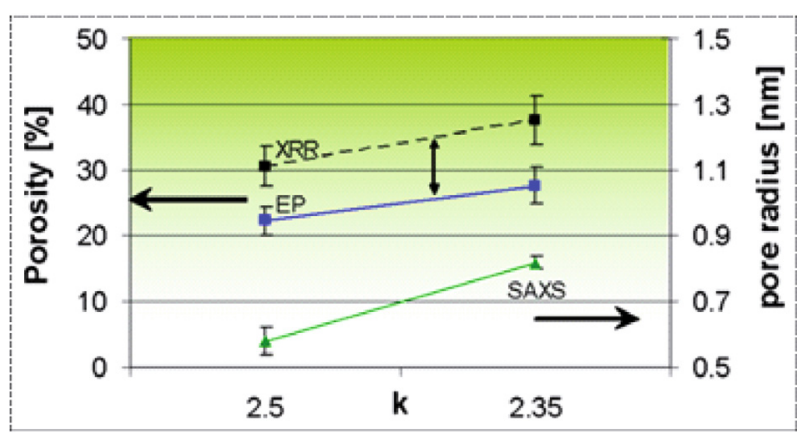

Fig. 19. (Color online) Pore radius (GI-SAXS, $600 \mathrm{~s}$ ) and Porosity (XRR \& EP) of two different ULK films.

Table 2. Porosity parameters of two porous low- $\kappa$ layers.

\begin{tabular}{|c|c|c|c|c|}
\hline & \multicolumn{2}{|c|}{ Porosity $P(\%)$} & \multicolumn{2}{|c|}{ Pore radius $\langle r\rangle(\mathrm{nm})$} \\
\hline Low- $\kappa$ & XRR & $\mathrm{EP}$ & GI-SAXS & $\mathrm{EP}$ \\
\hline \multirow[t]{3}{*}{ A } & 30 & 32 & 1.00 & 0.85 \\
\hline & & & & and \\
\hline & & & & 1.32 \\
\hline B & 23 & 22 & 0.71 & - \\
\hline
\end{tabular}

Table 3. Statistical value of the measurement system variation and respective acquisition time for $330 \mathrm{~nm}$ thick low- $\kappa$ film measurement.

\begin{tabular}{cccc}
\hline Technique & Dr & $\mathrm{P} / \mathrm{T}(\%)$ & Time/site $(\mathrm{s})$ \\
\hline $\mathrm{XRR}$ & 7.3 & 2.85 & 30 \\
$\mathrm{SE}$ & 110.3 & 0.62 & 5 \\
\hline
\end{tabular}

Tolerance Ratio. The smaller the $\% \mathrm{P} / \mathrm{T}$ value $(<10 \%)$ and the higher the Dr value $(>4)$, the smaller the changes that can be detected by the metrology tool. Both XRR and SE performed well, satisfying the $\mathrm{Dr}, \% \mathrm{P} / \mathrm{T}$ and speed criteria (Tab. 3).

However, XRR presents an advantage over SE in terms of the range of values that can be measured without varying the fitting parameters. Indeed, for the XRR technique the fitting parameters are set using a wide variation range around a targeted value as opposed to the narrow variation range used to set fitting parameters in ellipsometry (SE). For conditions in which wafers were processed with parameters varying by $10 \%$ around the standard process conditions, SE measurements required several recipe developments in order to provide accurate thickness measurements whereas XRR measurements were carried out over the entire wafer set with a single standard recipe.

Using grazing incidence reflection geometry, the GISAXS signal arises from variations of electron density (scattering length) occurring over distances exceeding the inter-atomic spacing in solids. Such variations occur when a solid contains pores. Details of the porosity (pore size and distribution) can be obtained from measurements of the angular distribution of scattered X-ray intensity $I(q)$ (Fig. 1) and modelled by assuming a distorted wave Born approximation for describing X-rays scattering from imperfect structures. $I(q)$, the X-ray intensity scattered by

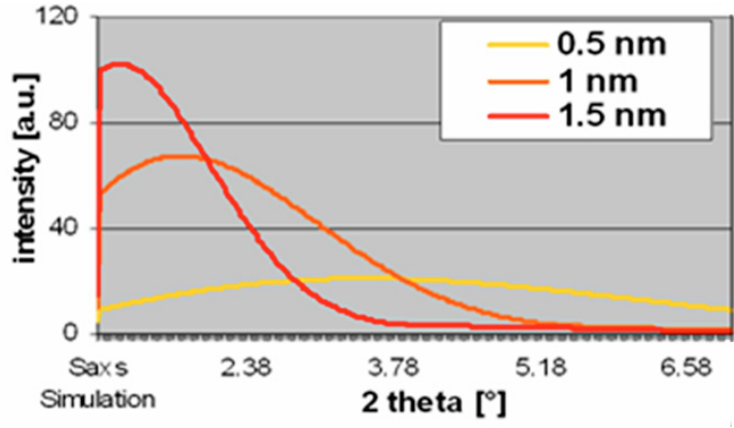

Fig. 20. (Color online) Modelled GI-SAXS spectra induced by pores exhibiting various radiuses: $0.5,1$ and $1.5 \mathrm{~nm}$ in the investigated low- $\kappa$ dielectrics, considering a log-normal distribution of the pore radius.

pores with an average radius $r$, can be expressed as [48]:

$$
I(q)=c \int_{0}^{\infty} n(r) f(q r) S(q r) d r
$$

where $c$ is a constant, $q$ is the scattering vector $(q=$ $4 \pi / \lambda \sin \theta / 2), \lambda$ is the incident X-ray wavelength, $\theta$ is the scattering angle, $n(r)$ is the pore radius distribution, $f(q r)$ is the spherical form factor:

$$
f(q r)=\frac{3 V_{0}}{q r^{3}}[\sin (q r)-q r \cos (q r)] .
$$

$V_{0}$ is the pore volume and $S(q r)$ is the structure factor for the mono-disperse hard sphere model [49].

We used a model to determine the average pore size from the GI-SAXS pattern. It is based on two assumptions: (i) all pores have a spherical shape; and (ii) the pore size has a log-normal distribution. This appears to be the best approach to model the GI-SAXS pattern [48]:

$$
n(r)=\frac{1}{(2 \pi)^{0,5} r_{0} \sigma \exp \left(0,5 \sigma^{2}\right)} \exp \left\{\frac{-\left[\ln \left(r / r_{0}\right)\right]^{2}}{2 \sigma^{2}}\right\}
$$

where $r_{0}$ is the pore radius corresponding to the maxima of the distribution, $s$ is related to the width of the distribution, and $n(r)$ is the number fraction with pore radius $r$.

This model predicts the variations of $I(q)$ as a function of the pore radius $r$ and of the overall porosity. The $\theta$ angle (which is equivalent to the scattering vector in the model we used) value which corresponds to the maximum scattering intensity relates to the average pore radius $r_{o}$. For smaller pores (small $r$ ) the scattered intensity is maximum for higher values, while for larger pores the scattered intensity moves to smaller values (Fig. 20). A larger overall porosity of the porous film induces an increase of the scattered intensity but doesn't affect the coordinates of the scattered intensity maximum, unless the increase of the overall porosity is the result of a larger pore size.

The GI-SAXS technique has been evaluated by $10 \times$ repeat measurements on a $330 \mathrm{~nm}$ thick low- $\kappa$ film using 3 different acquisition times, 400, 600 and $1200 \mathrm{~s}$. Relative 
Standard Deviation did not vary with acquisition time, remaining below $6 \%$, which translates into a size variation of $0.04 \mathrm{~nm}$ for pore radii measured at $0.6 \mathrm{~nm}$. Thus, all subsequent GI-SAXS measurements were performed with a $600 \mathrm{~s}$ acquisition time which appears to be the best trade-off between accuracy, signal to noise ratio and cycletime.

Two porogen based low- $\kappa$ films with $\kappa$ values equal to 2.5 and 2.35 were measured using XRR, GI-SAXS and EP. During the EP measurement, the shape of the adsorption/desorption isotherms indicated a fast filling of the micropores by toluene in the low- $\kappa$ material. For the $\kappa=2.5$ low $-\kappa$ film, the pore size distribution showed a large amount of micropores $(r=0.75 \mathrm{~nm})$ co-existing with mesopores $(r=1.2 \mathrm{~nm})$. For the film with $\kappa=2.35$, we found mainly mesopores $(r=1.3 \mathrm{~nm})$ with relatively less micropores.

For both types of films, GI-SAXS measurements have yielded radii ranging from 0.6 to $0.8 \mathrm{~nm}$ corresponding roughly to the micropores measured by EP (Fig. 19).

The open porosity of the low- $\kappa$ films has been measured by EP. A comparison with the overall porosity, which is calculated from the density measurements done by XRR assuming a skeleton density of $1.7 \mathrm{~g} \mathrm{~cm}^{-3}$, revealed a closed porosity present in those films close to $6 \%$.

\section{X-ray metrology of $\mathrm{Cu}$ interconnects}

$\mathrm{Cu}$ interconnects are manufactured using the Damascene method which consists in etching the insulating low- $\kappa$ layers, depositing a thin metallic film (Ta/TaN film stack) to prevent $\mathrm{Cu}$ diffusion inside the low- $\kappa$ film, depositing a thin $\mathrm{Cu}$ layer as a seed for the electrochemical deposition (ECD) of the thick Cu layer, depositing the ECD Cu layer inside the via and the interconnect lines and performing CMP of the excess $\mathrm{Cu}$ on the wafer's surface (Fig. 21).

Continuous downsizing of MOS transistor dimensions generates a reduction of $\mathrm{Cu}$ line and via dimensions. Moreover, since the reduction of line and via dimensions leads to an increase of the overall $\mathrm{Cu}$ line electrical resistivity, the thicknesses of the diffusion barrier and of the $\mathrm{Cu}$ seed layer, which are more resistive than ECD $\mathrm{Cu}$, must also be reduced.

Metrology requirements to guarantee proper process control of $\mathrm{Cu}$ interconnects are very demanding. They include monitoring the individual thicknesses, the allotropic phase and texture of the $\mathrm{Cu}$ diffusion barrier layer, the texture of the thick ECD Cu layer, and monitoring of dishing in $\mathrm{Cu}$ lines (Fig. 21b).

Since the constitutive elements involved in the $\mathrm{Cu}$ Damascene method exhibit a high electron density contrast among each other: 4040, 3380, 2460 and $420 \mathrm{~nm}^{-3}$ for $\mathrm{Ta}, \mathrm{TaN}, \mathrm{Cu}$ and the low- $\kappa$ material, respectively, and since the X-ray fluorescence efficient of $\mathrm{Ta}$ and $\mathrm{Cu}$ is very high, the combination of XRR and XRF is perfectly suited for the process control of film thickness in $\mathrm{Cu}$ Damascene. $\mathrm{XRR}$ is generally used during the process development on monitor wafers, while XRF is used on product wafers for process control, due to its small spot size $(18 \mu \mathrm{m}$ FWHM

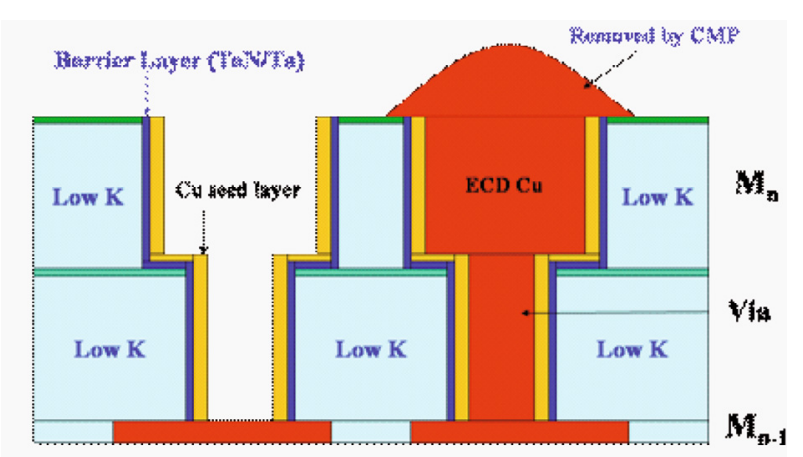

a) Schematic integration of a Damascene $\mathrm{Cu}$ level

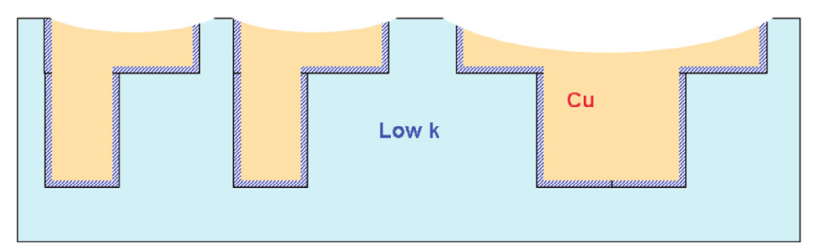

\section{b) $\mathrm{CMP}$ impact on $\mathrm{Cu}$ lines topology}

Fig. 21. (Color online) Integration of a Damascene $\mathrm{Cu}$ level.

for $\mathrm{Cu}$ ), which complies with metrology box dimensions $\left(70 \times 70 \mu \mathrm{m}^{2}\right)$. The potential of the combined use of XRR and XRF to monitor $\mathrm{Cu}$ interconnect related processes has already been shown in previous papers [50,51].

The excellent sensitivity of XRR to any change in electron density, and consequently, to any change in chemical composition of a layer stack can be shown by investigating $\mathrm{Ta} / \mathrm{TaN}$ barriers. Two kinds of $\mathrm{Ta} / \mathrm{TaN}$ barriers were deposited using two different PVD processes on monitor wafers:

- the standard Ionized-Sputtering process with target thickness for TaN and Ta respectively equal to $14 \mathrm{~nm}$ and $10 \mathrm{~nm}$;

- the improved process (TaN $6 \mathrm{~nm}+\mathrm{Ta} 18 \mathrm{~nm}$ ) with an $\mathrm{Ar}^{+}$sputter etch step between the TaN and Ta deposition steps. The sputter etch is used to obtain complete etching of the TaN film at the bottom of the contact with a slight recess in the underlying $\mathrm{Cu}$ line in order to minimize the contact resistance between $\mathrm{Ta}$ and $\mathrm{Cu}$ and to leave a good $\mathrm{Ta} / \mathrm{TaN}$ barrier integrity on the sidewalls of the contact.

XRR patterns of both barriers exhibit nearly the same main frequency of the fringes, indicating that the total thickness of the $\{\mathrm{Ta}-\mathrm{TaN}\}$ stacks is similar (Fig. 22a). On the other hand, differences can be observed in the middle part of the XRR spectra which accounts for differences in the respective thicknesses of TaN and Ta targeted in each processes. Moreover the extreme sensitivity of X-rays being reflected at interfaces between materials of different electronic densities is illustrated in the insert of Figure 22 showing the mass-density profiles of each barrier stack. 


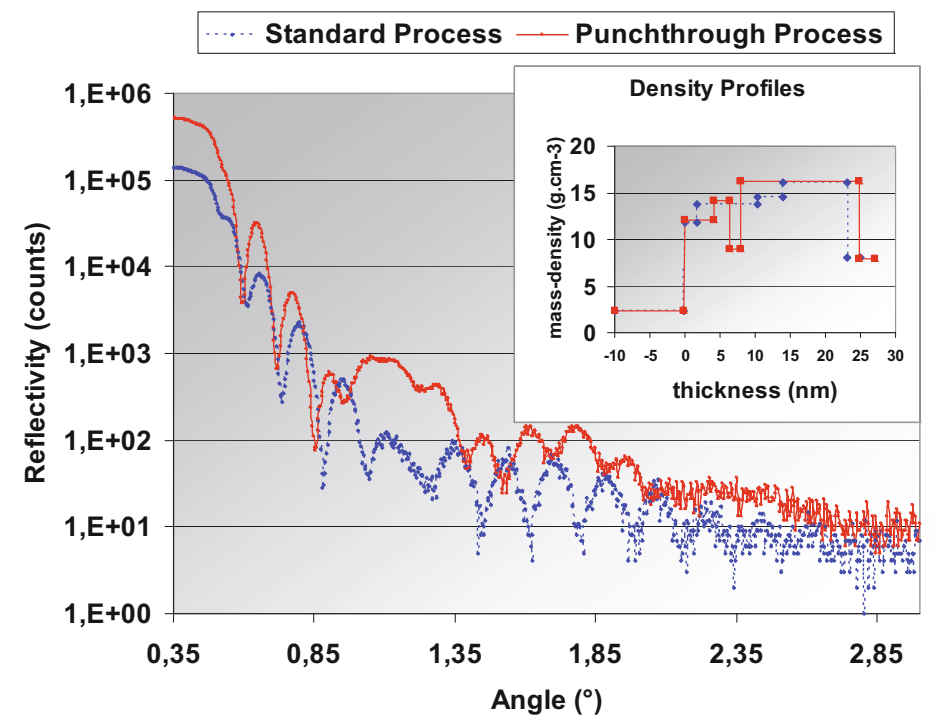

a) XRR experimental spectra of $\mathrm{Ta} / \mathrm{TaN}$ bi-layers deposited using standard and improved deposition processes. Inlet: mass density profiles of the bi-layers determined from the XRR spectra
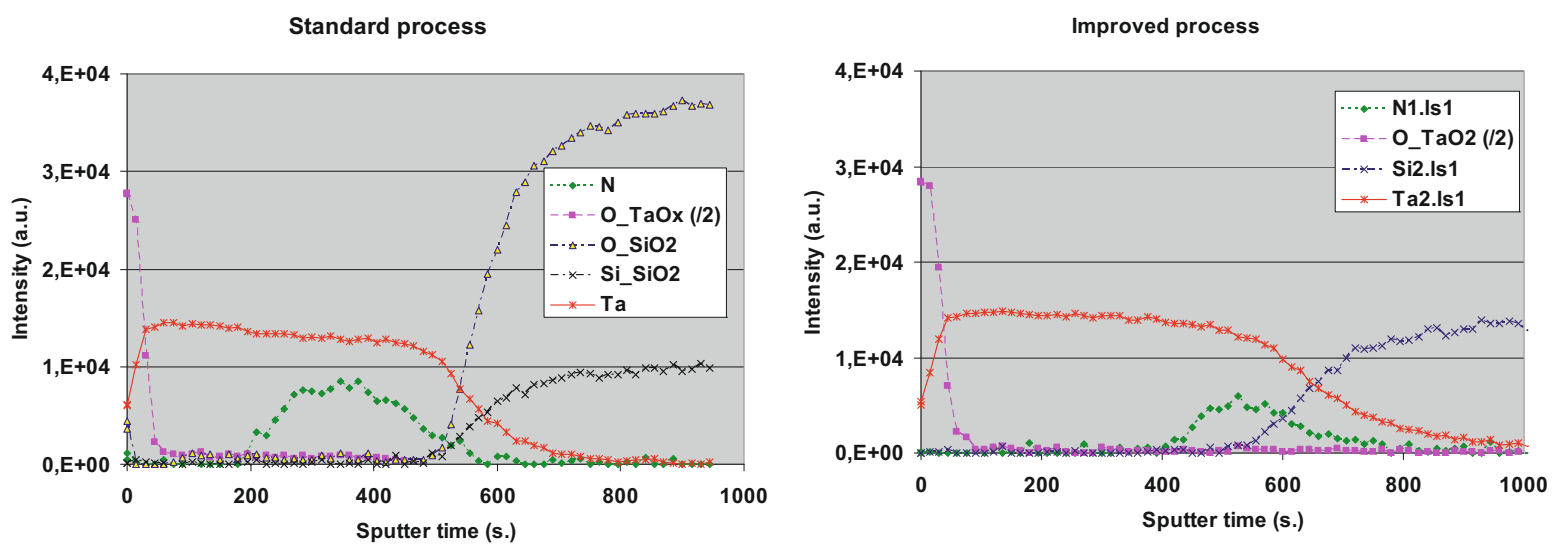

b) Auger depth profiles of $\mathrm{Ta} / \mathrm{TaN}$ bi-layers deposited using standard and improved processes

Fig. 22. (Color online) XRR patterns and Auger depth profiles of Ta/TaN film stack.

Whereas a Ta rich TaN (probably $\mathrm{Ta}_{2} \mathrm{~N}$ ) interface exists at the TaN-Ta interface of the standard process, a thin interface of low-density and high roughness has been outlined in the improved process.

Auger electron spectroscopy (AES) profiling of O, N and Ta was performed to validate the XRR model of both types of barriers (Fig. 22b). The O profiles clearly show the presence of a $2 \mathrm{~nm}$ thick oxidized top layer, whereas the $\mathrm{N}$ profile of the improved process indicates that there is a thinner TaN with less nitrogen and therefore a little bit denser: $14.2 \mathrm{~g} \mathrm{~cm}^{-3}$ versus $13.8 \mathrm{~g} \mathrm{~cm}^{-3}$. The thin, rough and low-density interface between $\mathrm{TaN}$ and $\mathrm{Ta}-$ as seen with XRR on the improved barrier - has no link with anomalous $\mathrm{N}$ content, but rather with a "weak" interface which accounts for the efficiency of the etching step performed between the TaN and Ta depositions. As is also shown by the $\mathrm{O}$ signal in the AES analysis, the standard barrier was grown on $\mathrm{SiO}_{2}$ and the other barrier directly onto Si. Correspondingly, the XRR analysis shows a thin- ner $\mathrm{TaSi}_{x}$ interface for the standard barrier than for the improved barrier.

Due to its natural spot length induced by the grazing incidence geometry, XRR can only be used on specific and long test structures for monitoring film thickness on patterned or product wafers. Monitoring of $\mathrm{Cu}$ film thickness was achieved on pads and test structures. These test structures are currently used to monitor the electrical properties of $\mathrm{Cu} /$ low- $\kappa$ interconnects. They consist of arrays of combs and serpentines; the comb and serpentine widths are called line widths $(L)$, while the space between comb and/or serpentine is referred to as the space width $(s)$. The $\mathrm{Cu}$ density is the ratio between the area occupied by the $\mathrm{Cu}$ combs and serpentines on the whole test structure area. $L$ and $s$ vary respectively in the $(0.5-40 \mu \mathrm{m})$ and $(0.5-68 \mu \mathrm{m})$ ranges, while the $\mathrm{Cu}$ density varies from 15 to $90 \%$.

In the small incident angle range $\left(0.4-0.9^{\circ}\right)$, the XRR pattern of an $800 \times 1500 \mu \mathrm{m}^{2} \mathrm{Cu}$ pad presents some 


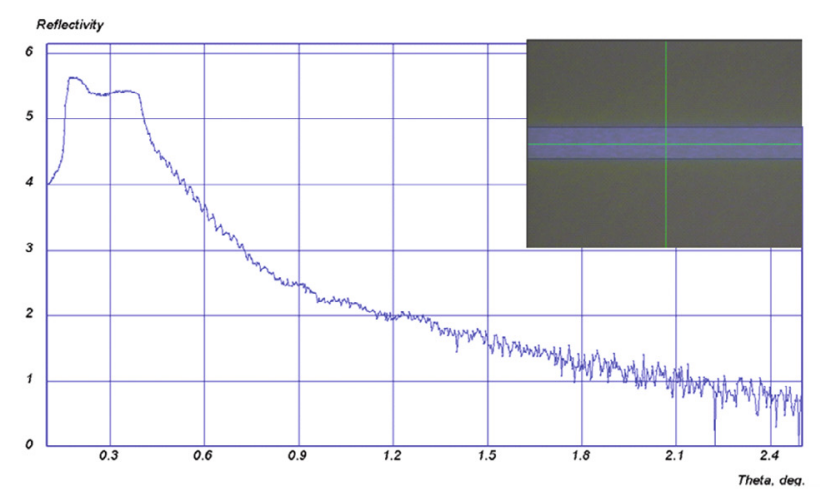

a) XRR pattern of a $800 \times 1500 \mu \mathrm{m} \mathrm{Cu} \mathrm{Pad}$

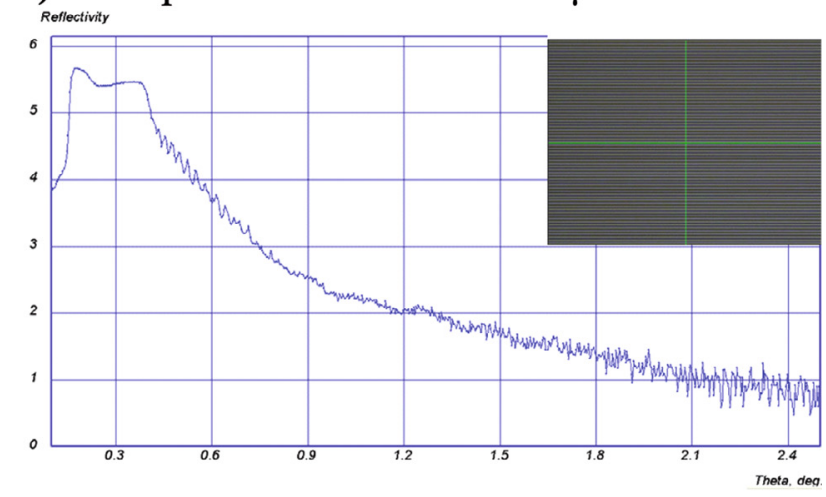

b) XRR pattern of a test structure: line $8 \mu \mathrm{m}$, space $2 \mu \mathrm{m}, \mathrm{Cu}$ density $80 \%$

Fig. 23. (Color online) XRR patterns on $\mathrm{Cu}$ test structures. Insets: optical micrographs of the measured test structures.

interference fringes, which are characteristic of the $\mathrm{Cu}$ film thickness (Fig. 23a). By performing the Fourier transform of the XRR pattern, we are able to accurately measure the $\mathrm{Cu}$ film thickness of the investigated pad.

The same experiments have been repeated on several $1.5 \times 1.5 \mathrm{~mm}^{2}$ comb/serpentine test structures. The XRR pattern of a low $\mathrm{Cu}$ density test structure does not exhibit well defined interference fringes. The weak amplitude of the fringes prevents performing a reliable Fourier transform of this spectrum; the $\mathrm{Cu}$ film thickness cannot be accurately determined.

On the other hand, XRR patterns of medium and large $\mathrm{Cu}$ density test structures exhibit interference fringes with amplitudes conducive to the determination of the $\mathrm{Cu}$ film thickness using the Fourier transform of the XRR patterns (Fig. 23b).

Since the $\mathrm{Cu}$ density was in the 15 to $90 \%$ range, we estimate that the $\mathrm{Cu}$ film thickness of such test structures can be determined when the $\mathrm{Cu}$ density is higher than $60 \%$. The $\mathrm{Cu}$ density is not the only parameter which affects the measurement accuracy. The width and length of the test structures also impacts the measurement accuracy; it is quite obvious that wider lines are better suited for XRR monitoring than narrow $\mathrm{Cu}$ lines. Nevertheless the $\mathrm{Cu}$ density was the most important criteria for XRR measurement viability.

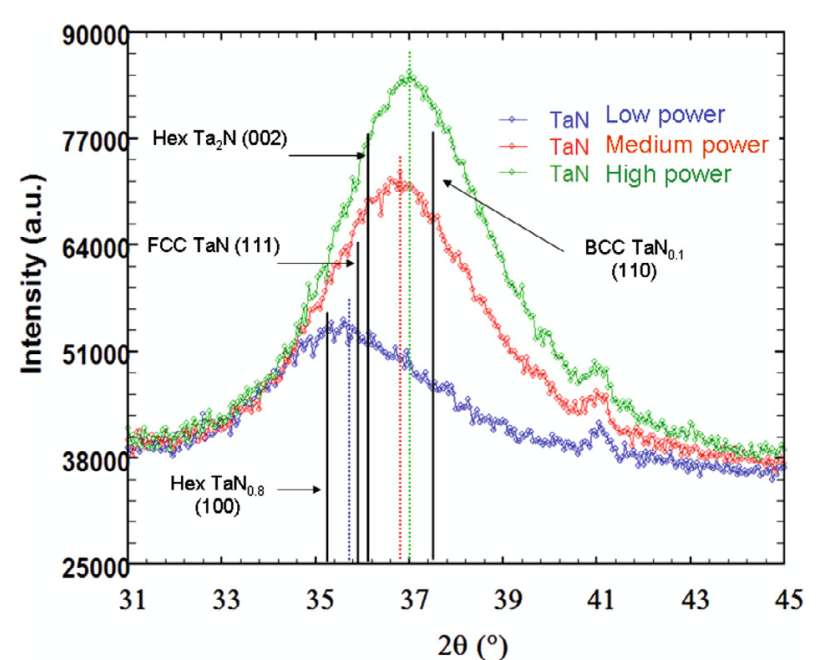

Fig. 24. (Color online) XRD patterns of $3 \mathrm{TaN}$ thin films deposited at various bias power.

This study demonstrates that XRR can be used in the scribe lines of product wafers but also on dedicated large test structures, which are used, for example, to monitor and adjust $\mathrm{Cu}$ CMP process steps.

Control of the crystallographic properties of thin films and thicker layers making up $\mathrm{Cu}$ interconnects is mandatory to optimize advanced processes (for instance, CMP erosion rate is sensitive to $\mathrm{Cu}$ texture) and to improve $\leq 65 \mathrm{~nm}$ device reliability. X-ray diffraction is widely used in off-line characterization laboratories to determine crystallographic phases, texture and grain size of polycrystalline thin films.

ECD $\mathrm{Cu}$ layer texture and grain size are highly sensitive to the allotropic phase and texture of the underlying Ta film, which are in turn affected by the crystallographic properties of the underlying TaN layer which depends on the nitrogen content in the TaN film.

Furthermore, the resistivity of Ta films strongly depends on their allotropic phase. $\alpha$-Ta is a cubic phase exhibiting an electrical resistivity ranging from 15 to $60 \mu \Omega \mathrm{cm}$, while $\beta$-Ta is a metastable tetragonal phase with an electrical resistivity ranging from 170 to $210 \mu \Omega \mathrm{cm}$. TaN is usually crystallized with a metastable cubic phase and its electrical resistivity is nearly $380 \mu \Omega \mathrm{cm}$.

$\mathrm{XRD}$ is the only fully automated technique which can provide in-line relevant data about the crystallographic phase of the $\mathrm{Ta} / \mathrm{TaN}$ bi-layer, the texture and the grain size of $\mathrm{Cu}$ interconnects.

To demonstrate the capabilities of XRD as a metrology technique to monitor crystallographic properties of thin films, Figure 24 presents the XRD pattern of three TaN films with thicknesses around $10 \mathrm{~nm}$, deposited on product wafers at three different substrate bias powers. XRD patterns were measured using a $500 \mu \mathrm{m}$-spot size with an acquisition time of $60 \mathrm{~s}$ per site. The "high and medium power" TaN film XRD patterns exhibit two major phase components: the body cubic centred $\alpha$-Ta(N) and the hexagonal $\mathrm{Ta}_{2} \mathrm{~N}$ phases, while the "low power" $\mathrm{TaN}$ 
film XRD pattern is much wider and exhibits at least three components: the body cubic centred $\alpha-\mathrm{Ta}(\mathrm{N})$, the face cubic centred TaN and hexagonal TaN phases.

The crystalline properties of thick $\mathrm{Cu}$ layers and underlying Ta films can also be controlled using fast XRD on product wafers. The crystallographic properties of $90 \mathrm{~nm}$ periodic comb structures embedded in low- $\kappa$ layers were monitored to evaluate their impact on device reliability. In this study, PVD Ta/TaN films only presented the cubic $(\alpha-\mathrm{Ta})$ and the meta-stable tetragonal phase $(\beta-\mathrm{Ta})$. Figure 25a presents the $\alpha$-Ta concentration contour, which was determined from the ratios of the $\alpha$-Ta (110) to the $\beta$-Ta (212) diffraction peak heights for each measured point. The $\alpha$-Ta content ranges from 0.75 to 0.98 , which means that the $\beta$-Ta content is quite low and ranges between 0.02 and 0.25 . The $\mathrm{Cu}$ grain size map, obtained using fast XRD, is well correlated with the $\beta$-Ta content map: an increase in $\beta$-Ta or a decrease of $\alpha$-Ta content leads to bigger $\mathrm{Cu}$ grain sizes (Fig. 25b). The bigger $\mathrm{Cu}$ grain size can be attributed to the higher mobility of $\mathrm{Cu}$ on $\alpha$-Ta than on $\beta$-Ta [52].

Combining XRR for monitoring the thickness and XRD for controlling the texture allows for tuning and optimizing the whole TaN film deposition process.

\section{X-ray metrology of MIM capacitors}

The fast and huge expansion of telecommunication and multimedia applications has driven the integration of complete system-on-chip (SoC) merging analog and digital processing units. Such mixed-signal integrated circuits require the integration of key passive components, such as inductors and capacitors.

Metal-Insulator-Metal (MIM) capacitors are widely used as filters and decouplers in RF devices and mixed signal integrated circuits. The key figures of merit of MIM capacitors are capacitance density, low leakage current, high breakdown voltage and reduced capacitance nonlinearity.

In order to reduce the surface of MIM capacitors in silicon devices, they are generally integrated circuits in metal interconnects, either as planar or three-dimensional capacitors (Fig. 26a). To further reduce the overall capacitor area, MIM capacitors, which use $\mathrm{SiO}_{2}$ or $\mathrm{Si}_{3} \mathrm{~N}_{4}$ (leading to 1 and $2 \mathrm{fF} \mu \mathrm{m}^{-2}$, respectively) as an insulator, are being progressively replaced by MIM capacitors having a high- $\kappa$ layer.

We investigated in detail the integration of planar MIM capacitors based on $\mathrm{TiN} / \mathrm{Ta}_{2} \mathrm{O}_{5} / \mathrm{TiN}$ film stacks (Fig. 26b). The $\mathrm{Ta}_{2} \mathrm{O}_{5}$ films were deposited using two deposition methods: metal-organic chemical vapour deposition (MOCVD) and plasma enhanced atomic layer deposition (PEALD).

\subsection{X-ray metrology of MOCVD $\mathrm{Ta}_{2} \mathrm{O}_{5}$ films}

In this study, MOCVD $\mathrm{Ta}_{2} \mathrm{O}_{5}$ films were deposited at $350{ }^{\circ} \mathrm{C}$ between two $20 \mathrm{~nm}$ thick PVD TiN electrodes us-

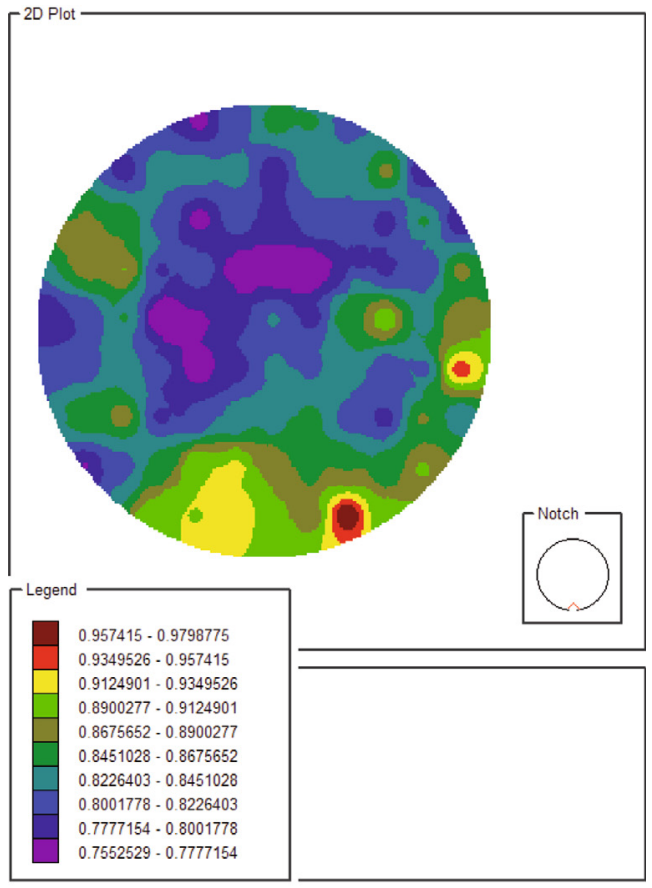

a)

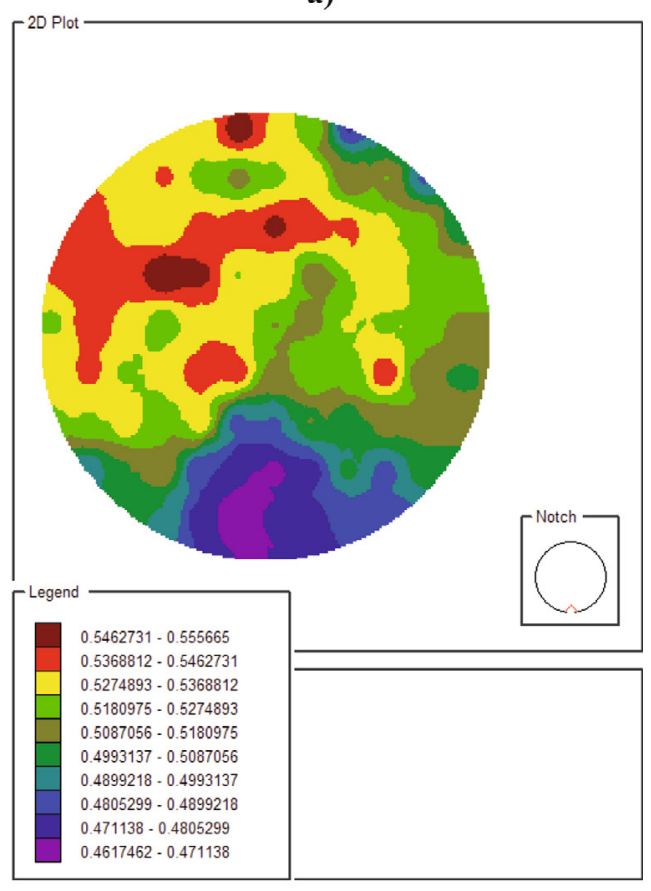

b)

Fig. 25. (Color online) (a) $\alpha$-Ta concentration and (b) $\mathrm{Cu}$ grain size parameter contour plots resulting from a 88 points $300 \mathrm{~mm}$ wafer map. Data collection was 185 s per point.

ing TBTDET: $\left(\mathrm{CH}_{3}\right)_{3} \mathrm{CN}=\mathrm{Ta}\left(\mathrm{N}\left(\mathrm{C}_{2} \mathrm{H}_{5}\right)_{2}\right)_{3}$ as the metalorganic precursor, $\mathrm{O}_{2}$ as the oxidizing agent and $\mathrm{N}_{2}$ as the carrier gas. A typical $\mathrm{Ta}_{2} \mathrm{O}_{5}$ film thickness is $45 \mathrm{~nm}$ in order to reach a $5 \mathrm{fF} \mu \mathrm{m}^{-2}$ capacitance.

Since TBTDET can leave impurities such as carbon, nitrogen and hydrogen inside the $\mathrm{Ta}_{2} \mathrm{O}_{5}$ films, the films are annealed under an oxidizing atmosphere: $\mathrm{NO}$ or $\mathrm{N}_{2} \mathrm{O}$, 


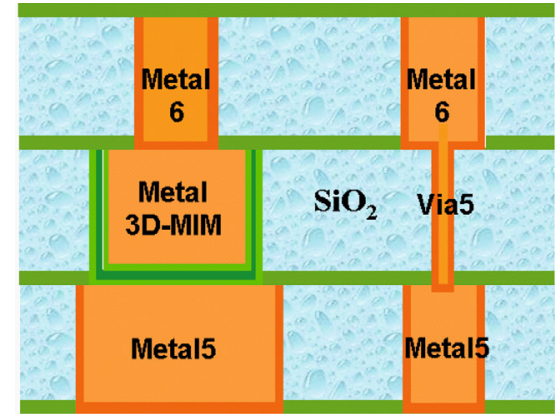

a) Schematic integration of a MIM capacitor in

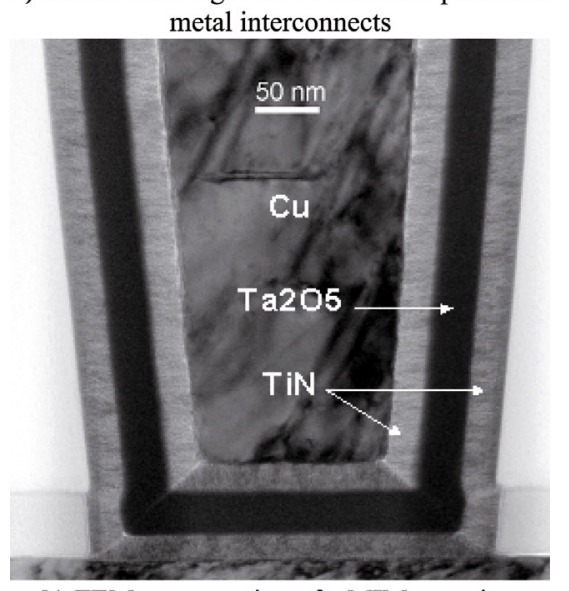

b) TEM cross-section of a MIM capacitor integrated in $\mathrm{Cu}$ interconnects

Fig. 26. (Color online) Integration of three-dimensional (3D)MIM capacitors in metal interconnects.

before the deposition of the top TiN electrode. This oxidizing anneal also repairs oxygen vacancies in the $\mathrm{Ta}_{2} \mathrm{O}_{5}$ film [52]. Cross-section TEM images of $\mathrm{TiN} / \mathrm{Ta}_{2} \mathrm{O}_{5} / \mathrm{TiN}$ stacks reveal the presence of $\mathrm{Ta}_{2} \mathrm{O}_{5} / \mathrm{TiN}$ interfaces and the presence of porosity inside the $\mathrm{Ta}_{2} \mathrm{O}_{5}$ film (Fig. 27a).

In order to determine the nature of the elements present at the bottom $\mathrm{Ta}_{2} \mathrm{O}_{5} / \mathrm{TiN}$ and top $\mathrm{TiN} / \mathrm{Ta}_{2} \mathrm{O}_{5}$ interfaces and the chemical compositions of these interfaces, elastic recoil detection analysis (ERDA) was carried out on with $\mathrm{Au}$ ions beam of $40 \mathrm{MeV} \mathrm{amu}^{-1}$ and Time-of-Flight (ToF) mass separation. This technique can provide the simultaneous determination of the absolute atomic concentrations and depth profiles of all involved elements, including hydrogen [53].

ERDA analyses demonstrate that the bottom and top interfaces mainly arise from the inter-diffusion of the main $\mathrm{Ti}, \mathrm{N}$ and $\mathrm{O}$ species, while Ta species tend to diffuse only at the bottom interface. The bottom interface is significantly larger than the top interface, which looks quite abrupt (Fig. 27b); the bottom interfacial width is around $10^{17}$ at. $\mathrm{cm}^{-2}$, while the top interfacial width is ten times lower.

Since the existence of interfacial films can strongly impact the electrical properties of MIM capacitors [54], we have done an in-depth study of the influence of experimental conditions (deposition temperature, anneal tem- perature and atmosphere) on the characteristics of bottom and top interfaces.

In-line XRR monitoring provides fast and valuable information about the physical properties of these interfaces (for example, thickness and density). XRR patterns of a $\mathrm{TiN} / \mathrm{Ta}_{2} \mathrm{O}_{5} / \mathrm{TiN}$ capacitor cannot be modelled as a trilayer (Fig. 28). The $\mathrm{Ta}_{2} \mathrm{O}_{5}$ film must be split in 3 sublayers; the 2 added sub-layers representing the top and bottom interfaces. While the main $\mathrm{Ta}_{2} \mathrm{O}_{5}$ film exhibits a mass-density of around $6.6 \mathrm{~g} \mathrm{~cm}^{-3}$, the interfacial layers exhibit higher mass-densities (Tab. 4), which results from the inter-diffusion of Ta, Ti, O and $\mathrm{N}$, as shown by ERDA.

According to the depth profile of a $\mathrm{TiN} / \mathrm{Ta}_{2} \mathrm{O}_{5} / \mathrm{TiN}$ capacitor, nitrogen is the main diffusing species (Fig. 27b). Since bulk TaN exhibits quite higher mass-density $13.7 \mathrm{~g} \mathrm{~cm}^{-3}$ than $\mathrm{Ta}_{2} \mathrm{O}_{5}\left(8.2 \mathrm{~g} \mathrm{~cm}^{-3}\right)$, diffusion of $\mathrm{N}$ in $\mathrm{Ta}_{2} \mathrm{O}_{5}$ should increase the mass-density of the interfacial layers.

XRR pattern modelling of $\mathrm{TiN} / \mathrm{Ta}_{2} \mathrm{O}_{5} / \mathrm{TiN}$ capacitors also revealed the low mass-density of the main $\mathrm{Ta}_{2} \mathrm{O}_{5}$ layer. The overall porosity of this layer was calculated using equation (17) assuming a bulk $\mathrm{Ta}_{2} \mathrm{O}_{5}$ mass-density of $8.2 \mathrm{~g} \mathrm{~cm}^{-3}$. The porosity of the main $\mathrm{Ta}_{2} \mathrm{O}_{5}$ film was calculated to be around $20 \%$ and was found to be dependent on the experimental conditions. Such a high porosity value for a high-k material affects the value of the $\mathrm{Ta}_{2} \mathrm{O}_{5}$ dielectric constant.

The pore microstructure of $\mathrm{Ta}_{2} \mathrm{O}_{5}$ layers has been monitored as a function of experimental conditions, using in-line GI-SAXS. The pore radius decreases from $1 \mathrm{~nm}$ down to $0.8 \mathrm{~nm}$ when the $\mathrm{Ta}_{2} \mathrm{O}_{5}$ layer thickness increases from 20 to $90 \mathrm{~nm}$. The reduction of the pore size with the increase in $\mathrm{Ta}_{2} \mathrm{O}_{5}$ layer thickness probably results from the increase in thermal budget coupled to the increase in thickness. The measured pore radius perfectly matches with the TBTDET molecule dimensions: $1 \times 0.8 \mathrm{~nm}$, which suggests that some TBTDET molecules were not dissociated during the deposition.

Off-line angle-resolved XPS (AR-XPS) analyses were performed for determining the chemical mechanisms involved during the formation of interfacial layers. $3 \mathrm{~nm}$ thick $\mathrm{Ta}_{2} \mathrm{O}_{5}$ films were deposited over TiN electrodes and, in another experimental set, $3 \mathrm{~nm}$ thick TiN films were deposited over $\mathrm{Ta}_{2} \mathrm{O}_{5}$ films. The small top layer thickness allows using AR-XPS without ion milling, which usually affects the accuracy of AR-XPS analyses. These bi-layers were deposited and annealed using the conventional experimental conditions.

AR-XPS of Ta- $4 f$ photoelectrons of the top $\mathrm{Ta}_{2} \mathrm{O}_{5}$ film deposited on TiN evidences the presence of $\mathrm{Ta}_{2} \mathrm{O}_{5}$, metallic Ta and, probably of TaN (Fig. 29a). The probable TaN occurrence could be induced by the $\mathrm{N}$ diffusion from TiN to $\mathrm{Ta}_{2} \mathrm{O}_{5}$. Since metallic $\mathrm{Ta}$ is also detected by the AR-XPS analyses when TiN is deposited over $\mathrm{Ta}_{2} \mathrm{O}_{5}$, the presence of metallic Ta ions could only arise from a strong oxide-reduction reaction between $\mathrm{Ta}_{2} \mathrm{O}_{5}$ and TiN, despite the oxidizing annealing step performed after $\mathrm{Ta}_{2} \mathrm{O}_{5}$ deposition. 


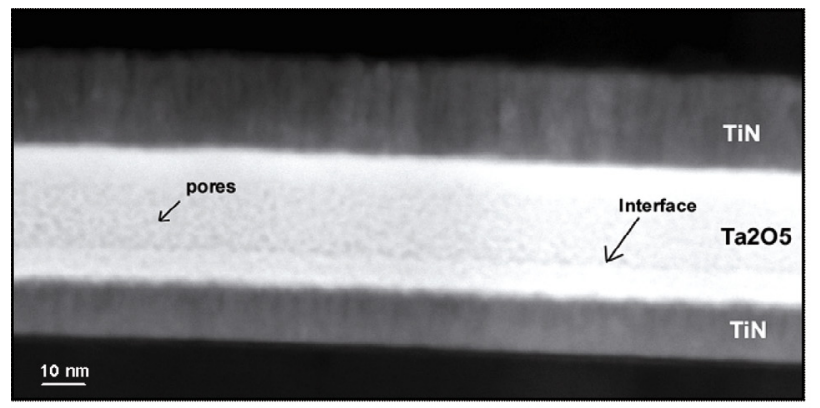

a) $\mathrm{TEM}$ cross-section of a $\mathrm{TiN} / \mathrm{Ta}_{2} \mathrm{O}_{5} / \mathrm{TiN}$ capacitor

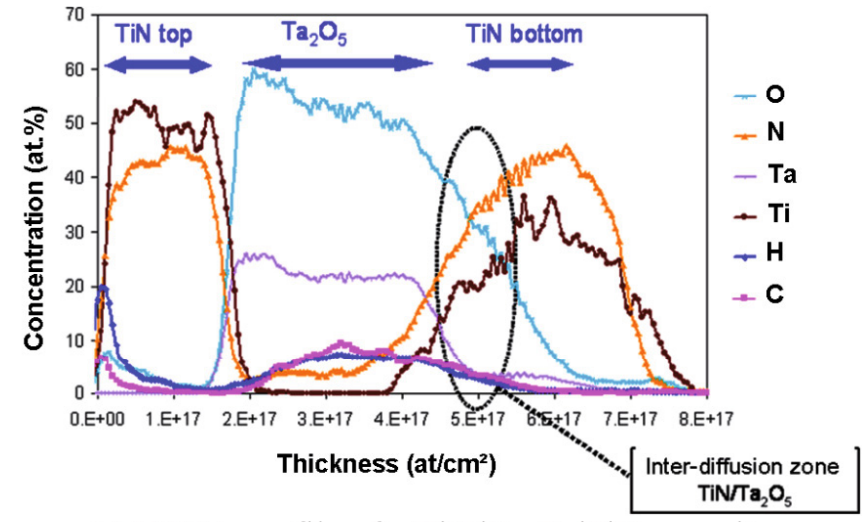

b) ERDA profile of a TiN/ $\mathrm{Ta}_{2} \mathrm{O}_{5} / \mathrm{TiN}$ capacitor

Fig. 27. (Color online) Morphology and chemical depth profile of a $\mathrm{TiN} / \mathrm{Ta}_{2} \mathrm{O}_{5} / \mathrm{TiN}$ capacitor.

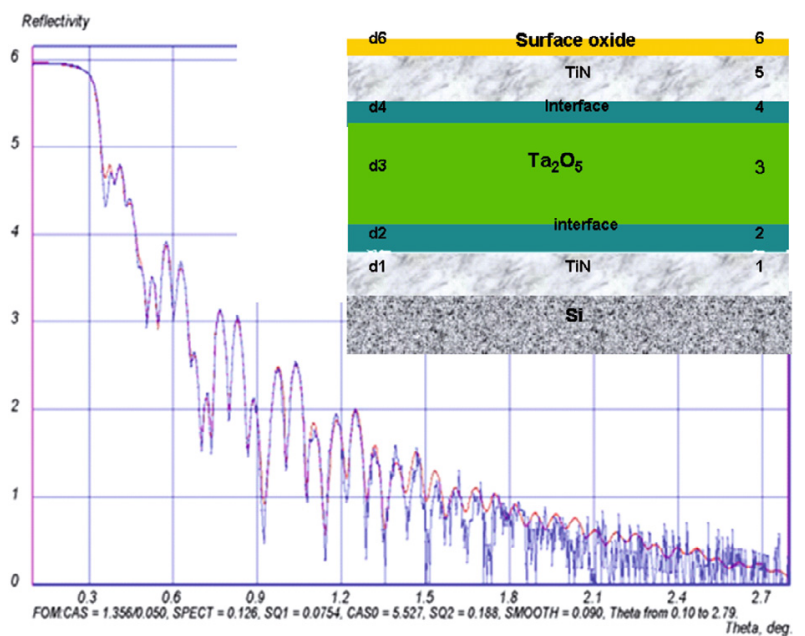

Fig. 28. (Color online) Experimental (blue) and modelled (red) XRR pattern of a $\mathrm{TiN} / \mathrm{Ta}_{2} \mathrm{O}_{5} / \mathrm{TiN}$ capacitor.

AR-XPS of Ti- $2 p$ photoelectrons of the top $\mathrm{Ta}_{2} \mathrm{O}_{5}$ film deposited on TiN electrode detects the occurrence of TiN, TiON, and $\mathrm{TiO}_{2}$ (Fig. 29b). The presence of these three species is commonly observed on TiN films; they generally arise from the progressive oxidation of the underlying TiN layer [54]. Nevertheless the $\mathrm{TiO}_{2}$ concentration should be very high due to reduction of $\mathrm{Ta}_{2} \mathrm{O}_{5}$ film. The presence of $\mathrm{TiO}_{2}$ at the $\mathrm{Ta}_{2} \mathrm{O}_{5} / \mathrm{TiN}$ interface can strongly impact the MIM capacitor properties, since $\mathrm{TiO}_{2}$ is a high- $\kappa$ material with a very low energy gap. Such a low energy gap will lower the barrier height of the TiN electrode and induce leakage current in the MIM capacitors.

\subsection{X-ray metrology of PEALD $\mathrm{Ta}_{2} \mathrm{O}_{5}$ films}

In order to improve MIM capacitor properties by improving layer interface control, MIM capacitors were prepared using the PE-ALD and the ALD methods.

TiN electrodes were deposited by PE-ALD at $350{ }^{\circ} \mathrm{C}$ using $\mathrm{TiCl}_{4}$ as the precursor and $\mathrm{NH}_{3}$ as the reactive agent. $\mathrm{N}_{2} / \mathrm{H}_{2}$ plasma was used to speed up the deposition
Table 4. Best film physical properties (mass-density and thickness) for fitting XRR pattern of MOCVD based MIM capacitors (Fig. 28).

\begin{tabular}{cccc}
\hline Film & $d(\mathrm{~nm})$ & $\rho\left(\mathrm{g} \mathrm{cm}^{-3}\right)$ & Porosity (\%) \\
\hline $\mathrm{TiO}_{x}$ & 3.4 & 4.50 & \\
$\mathrm{TiN}$ (top) & 14.3 & 5.03 & \\
I.L. (top) & 2.5 & 7.02 & \\
$\mathrm{Ta}_{2} \mathrm{O}_{5}$ & 37.3 & 6.62 & 20 \\
I.L. (bottom) & 2.4 & 7.55 & \\
TiN (bottom) & 11 & 4.62 & \\
\hline
\end{tabular}

rate. $\mathrm{Ta}_{2} \mathrm{O}_{5}$ films were deposited at around $300{ }^{\circ} \mathrm{C}$ using TEATO: $\mathrm{Ta}\left(\mathrm{OC}_{2} \mathrm{H}_{5}\right)_{5}$, as the precursor. Oxygen (plasma) was used as the reactive agent for the ALD (PE-ALD) deposition of $\mathrm{Ta}_{2} \mathrm{O}_{5}$ films.

ERDA analyses, using Au-40 MeV ions, showed that the interfaces of the $\mathrm{TiN} / \mathrm{Ta}_{2} \mathrm{O}_{5} / \mathrm{TiN}$ capacitor deposited using PE-ALD are more abrupt than those of the MOCVD MIM capacitor. $\mathrm{N}$ diffusion at the $\mathrm{Ta}_{2} \mathrm{O}_{5} / \mathrm{TiN}$ and $\mathrm{TiN} / \mathrm{Ta}_{2} \mathrm{O}_{5}$ interfaces was lower in the PE-ALD film stack (Fig. 30).

XRR patterns of PE-ALD TiN/ $\mathrm{Ta}_{2} \mathrm{O}_{5} / \mathrm{TiN}$ film stacks were modelled as MOCVD TiN/ $\mathrm{Ta}_{2} \mathrm{O}_{5} / \mathrm{TiN}$ film stacks; the $\mathrm{Ta}_{2} \mathrm{O}_{5}$ layer was split into 3 sub-layers. Additional sub-layers were treated as interfacial layers exhibiting mass-densities of 7.34 and $8.06 \mathrm{~g} \mathrm{~cm}^{-3}$, for the top and bottom interfaces, respectively (Tab. 5). The mass-densities of the interfacial layers in PE-ALD $\mathrm{TiN} / \mathrm{Ta}_{2} \mathrm{O}_{5} / \mathrm{TiN}$ film stacks were much higher than those found for the MOCVD TiN/ $\mathrm{Ta}_{2} \mathrm{O}_{5} / \mathrm{TiN}$ film stack and given in Table 4.

The mass-density of the main $\mathrm{Ta}_{2} \mathrm{O}_{5}$ film deposited by PE-ALD $\left(7.32 \mathrm{~g} \mathrm{~cm}^{-3}\right)$ was higher than the MOCVD $\mathrm{Ta}_{2} \mathrm{O}_{5}$ film mass-density $\left(6.62 \mathrm{~g} \mathrm{~cm}^{-3}\right)$. PE-ALD $\mathrm{Ta}_{2} \mathrm{O}_{5}$ film exhibited porosity close to $8 \%$ (Tab. 5). The decrease in porosity of the PE-ALD $\mathrm{Ta}_{2} \mathrm{O}_{5}$ film naturally induced an increase of the dielectric constant, compared to the dielectric constant of MOCVD $\mathrm{Ta}_{2} \mathrm{O}_{5}$ layers as determined by $C(V)$ measurements (Fig. 31). 


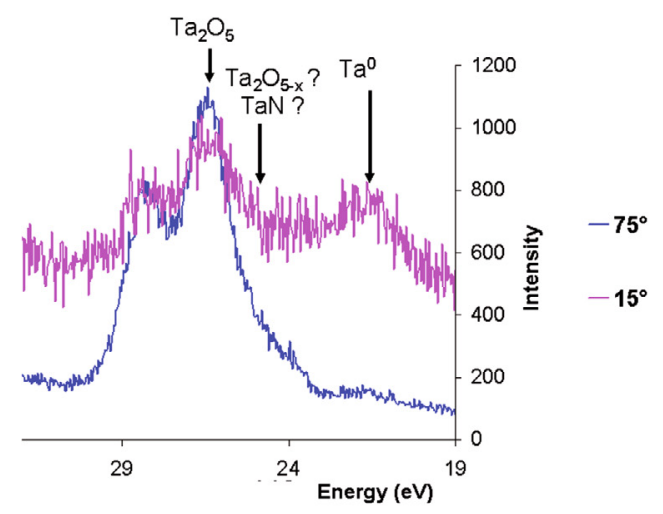

a) ARXPS - Ta- $4 f$ photoelectrons from a $3 \mathrm{~nm}$ thick $\mathrm{Ta}_{2} \mathrm{O}_{5}$ over TiN after annealing

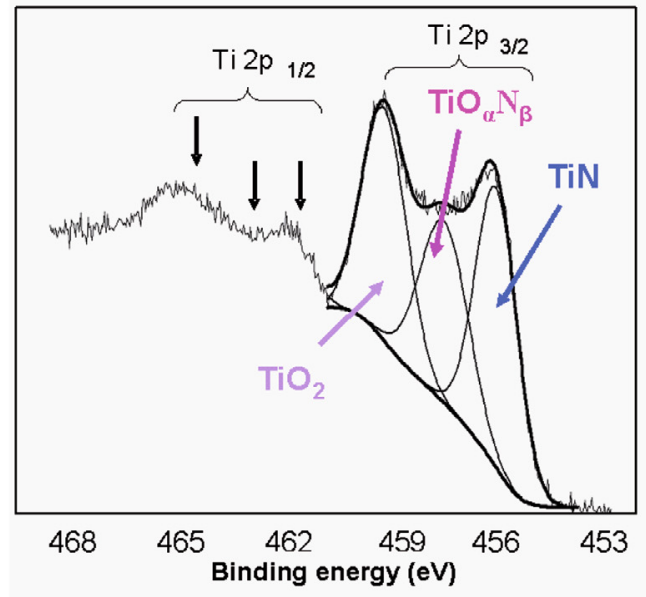

b) ARXPS - Ti- $2 p$ photoelectrons from a $3 \mathrm{~nm}$ thick $\mathrm{Ta}_{2} \mathrm{O}_{5}$ over TiN after annealing

Fig. 29. (Color online) AR-XPS of a $3 \mathrm{~nm}$ thick $\mathrm{Ta}_{2} \mathrm{O}_{5}$ over TiN after annealing.

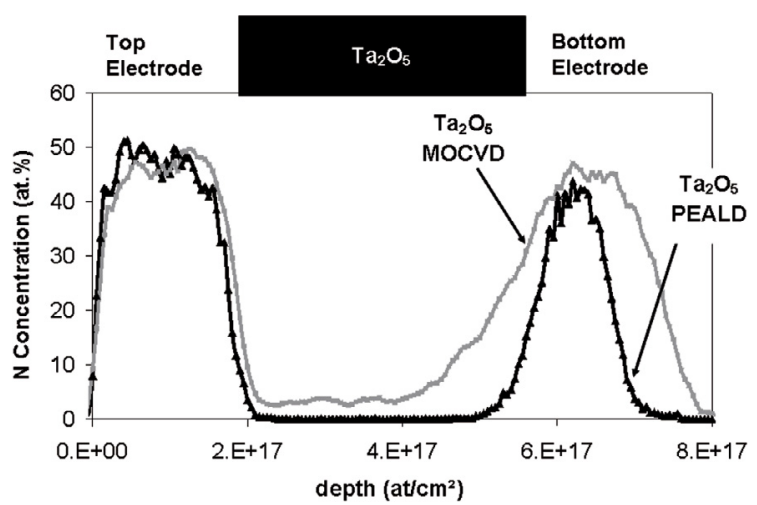

Fig. 30. $\mathrm{N}$ profile (ERDA) of $\mathrm{TiN} / \mathrm{Ta}_{2} \mathrm{O}_{5} / \mathrm{TiN}$ capacitor for MOCVD and PE-ALD $\mathrm{Ta}_{2} \mathrm{O}_{5}$ films.

AR-XPS analyses of $3 \mathrm{~nm}$ thick $\mathrm{Ta}_{2} \mathrm{O}_{5}$ films deposited using MOCVD, PE-ALD and ALD on TiN electrodes were performed to understand the behaviour of the $\mathrm{Ta}_{2} \mathrm{O}_{5} / \mathrm{TiN}$ interfaces. AR-XPS of Ta- $4 f$ photoelectrons revealed that all three deposition methods lead to the formation of metallic Ta: $\mathrm{Ta}^{0}$ (Fig. 32a). XPS spectra of ALD and MOCVD $\mathrm{Ta}_{2} \mathrm{O}_{5}$ films were quite similar, while the XPS

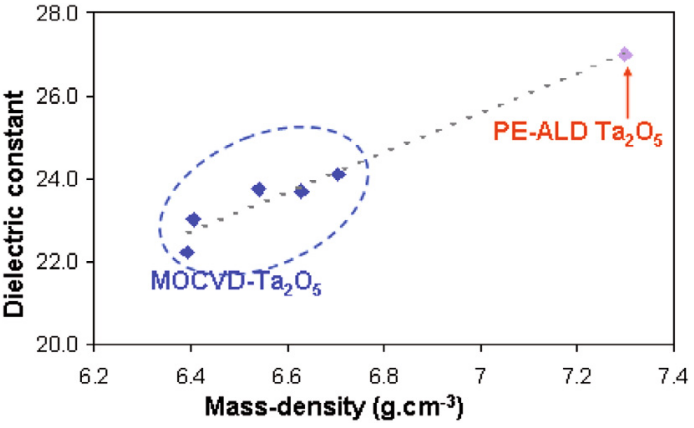

Fig. 31. (Color online) Variation of $\mathrm{Ta}_{2} \mathrm{O}_{5}$ dielectric constant as a function of mass-density monitored by XRR.

Table 5. Best film physical properties (mass-density and thickness) for fitting XRR pattern of PEALD based MIM capacitors.

\begin{tabular}{cccc}
\hline Film & $d(\mathrm{~nm})$ & $\rho\left(\mathrm{g} \mathrm{cm}^{-3}\right)$ & Porosity $(\%)$ \\
\hline $\mathrm{TiO}_{x}$ & - & - & \\
$\mathrm{TiN}$ (top) & 14.3 & 5.03 & \\
I.L. (top) & 2.1 & 7.34 & \\
$\mathrm{Ta}_{2} \mathrm{O}_{5}$ & 37.3 & 7.32 & 8 \\
I.L. (bottom) & 1 & 8.02 & \\
TiN (bottom) & 11 & 4.62 & \\
\hline
\end{tabular}

spectrum of PE-ALD $\mathrm{Ta}_{2} \mathrm{O}_{5}$ film exhibited an energy shift towards higher binding energies. Such an energy shift is characteristic of Ta ions with a higher oxidation level. This observation could imply than the concentration of oxygen vacancies in $\mathrm{PE}-\mathrm{ALD} \mathrm{Ta}_{2} \mathrm{O}_{5}$ films is lower than the ones in ALD and PE-ALD $\mathrm{Ta}_{2} \mathrm{O}_{5}$ films.

AR-XPS Ti- $2 p$ spectra of the same $\mathrm{Ta}_{2} \mathrm{O}_{5}$ films deposited on TiN (Fig. 32b) show that PE-ALD and MOCVD $\mathrm{Ta}_{2} \mathrm{O}_{5}$ deposited films tend to oxidize the underlying TiN electrode in a similar way; the ratio between the TiN and $\mathrm{TiO}_{2}$ peak intensity being 0.48 for the two deposition methods. While $\mathrm{ALD} \mathrm{Ta}_{2} \mathrm{O}_{5}$ film deposition leads to a very intense TiN peak intensity and a weak $\mathrm{TiO}_{2}$ peak intensity; the ratio between the $\mathrm{TiN}$ and $\mathrm{TiO}_{2}$ peak intensities is 0.82 . This result was corroborated by the ARXPS analyses of $\mathrm{N}-1 s$ photoelectrons: the ratio between the intensity of $\mathrm{NO}$ and $\mathrm{TiN}$ peaks is equal to $0.99,0.98$ and 0.84 for $\mathrm{Ta}_{2} \mathrm{O}_{5}$ films deposited by MOCVD, PE-ALD and ALD, respectively.

Compared to MOCVD and PE-ALD, the ALD method leads to $\mathrm{Ta}_{2} \mathrm{O}_{5}$ film deposition, which results in a lower oxidation of the underlying TiN electrode, compared to PE-ALD and MOCVD $\mathrm{Ta}_{2} \mathrm{O}_{5}$ film deposition methods.

These results indicate that XRR monitoring of $\mathrm{TiN} / \mathrm{Ta}_{2} \mathrm{O}_{5} / \mathrm{TiN}$ capacitors deposited using different methods can be used to optimize the $\mathrm{Ta}_{2} \mathrm{O}_{5}$ film deposition technique and experimental conditions to enhance MIM capacitor properties. Since PE-ALD $\mathrm{Ta}_{2} \mathrm{O}_{5}$ films exhibit higher mass-densities and higher dielectric constants than MOCVD $\mathrm{Ta}_{2} \mathrm{O}_{5}$ films, and because ALD $\mathrm{Ta}_{2} \mathrm{O}_{5}$ film does not excessively oxidize TiN electrodes, we prepared a MIM capacitor composed of PE-ALD TiN electrodes and 


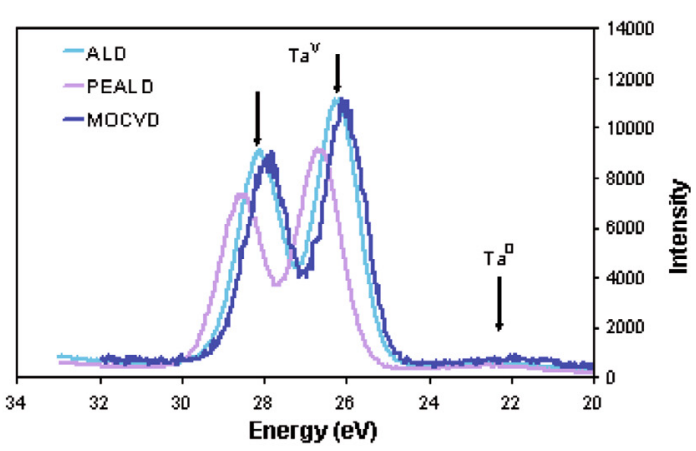

a) Ta- $4 f$ photoelectrons from a $3 \mathrm{~nm}$ thick $\mathrm{Ta}_{2} \mathrm{O}_{5}$ deposited by MOCVD, PE-ALD and ALD over TiN after annealing

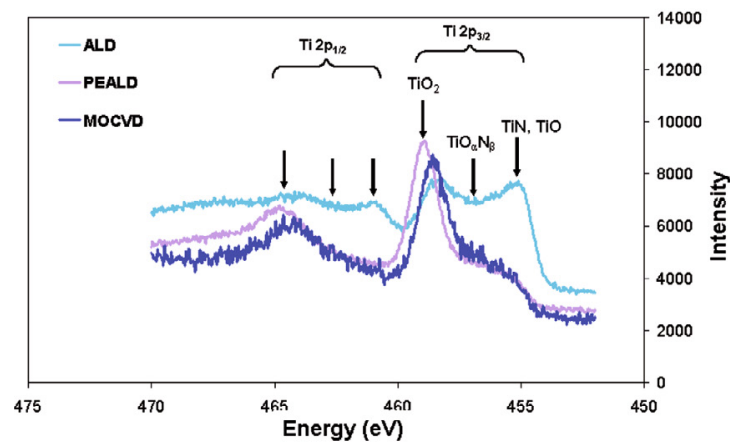

b) Ti- $2 p$ photoelectrons from a $3 \mathrm{~nm}$ thick $\mathrm{Ta}_{2} \mathrm{O}_{5}$ deposited by MOCVD, PE-ALD and ALD over TiN after annealing

Fig. 32. (Color online) AR-XPS of a $3 \mathrm{~nm}$ thick $\mathrm{Ta}_{2} \mathrm{O}_{5}$ deposited by MOCVD, PE-ALD and ALD over TiN after annealing.

a $6 \mathrm{~nm} \mathrm{ALD/33} \mathrm{nm} \mathrm{PE-ALD/6} \mathrm{nm} \mathrm{ALD} \mathrm{Ta} \mathrm{O}_{5}$ film stack as the insulator for combining the benefits of each $\mathrm{Ta}_{2} \mathrm{O}_{5}$ film deposition technique. Leakage current of this MIM capacitor was compared with the standard MOCVD MIM capacitor (Fig. 33). At $125{ }^{\circ} \mathrm{C}$ and $5 \mathrm{~V}$, the leakage currents of the hybrid ALD/PE-ALD-based MIM capacitor were two orders of magnitude lower than the MOCVDbased MIM capacitor [55].

This study about the effect of interface quality on MIM capacitor properties has led to the development of new capacitors based on hybrid dielectric stacks [56].

\section{Conclusions and perspectives}

The availability of bright $\mathrm{X}$-ray sources, optics for focusing $\mathrm{X}$-rays down to $10 \mu \mathrm{m}$ and efficient X-ray detectors has translated into the introduction of X-ray based techniques as in-line metrology methods for process control of MOS manufacturing and development.

Due to its small spot size, $\mathrm{X}$-ray fluorescence $(\mathrm{XRF})$ is perfectly suited to monitor $\mathrm{Cu}$ interconnect manufacturing processes using short acquisition times.

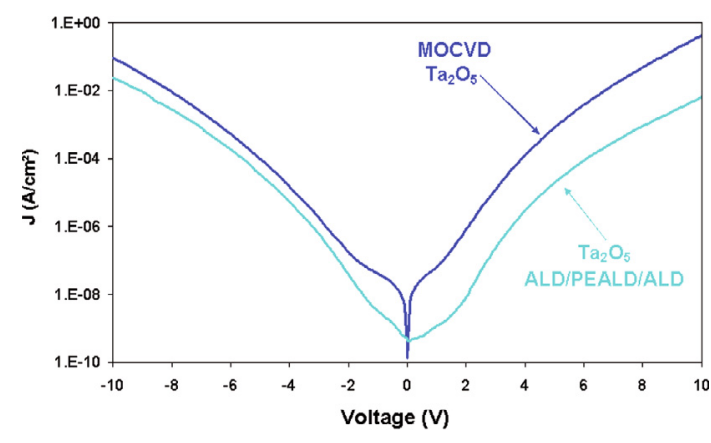

Fig. 33. (Color online) $I(V)$ characteristics of MOCVD and $\mathrm{PE}-\mathrm{ALD} \mathrm{TiN} / \mathrm{Ta}_{2} \mathrm{O}_{5} / \mathrm{TiN}$ capacitors at $125{ }^{\circ} \mathrm{C}[55]$.

Capability of X-ray reflectivity (XRR) for monitoring physical properties of dielectrics such as high- $\kappa$ and low- $\kappa$, as well as metal films has been proven with these works. XRR is very fast and convenient when developing new processes and integrating new materials. Due to its grazing geometry, XRR measurements on patterned wafers are more delicate, unless dedicated test structures are introduced for this purpose.

X-ray diffraction (XRD) appears to be compulsory for improving MOS transistor reliability by carefully monitoring thin film crystallographic properties.

Grazing-incidence-small angle X-ray scattering (GISAXS) is well suited to characterize crystalline defects and pores in low- $\kappa$ layers. However, the acquisition time needed to obtain a good signal to noise ratio is currently too long to use GI-SAXS as an in-line metrology method.

X-ray photoelectron spectroscopy (XPS) perfectly matches the requirements for the in-line monitoring of $\mathrm{SiON}$ gate dielectrics. XPS results can be used to accurately forecast the electrical properties of MOS transistors. The current and future applications of XPS are numerous for films thinner than $10 \mathrm{~nm}$ : high- $\kappa$, metal gate, silicide, diffusion barrier layer...

Due to the small wavelengths involved, X-ray metrology is now being investigated as a new technique to control the lithography process. Critical dimension small angle X-ray scattering (CDSAXS) is developed as a new metrology platform capable of measuring the average cross section and linewidth roughness (LWR) in lithography test patterns with pitches ranging from 10 to $500 \mathrm{~nm}$ with sub-nm precision [57].

Because of the development of brilliant x-sources, $\mathrm{X}$-ray optics and detectors is still progressing, off-line metrology using synchrotron X-rays is becoming a very powerful tool for nanoscale analysis. Transmission X-ray microscopy and X-ray tomography are now used to investigate the reliability of $\mathrm{Cu}$ interconnects [58]. $\mu$-spot X-ray diffraction can be used to characterize stress in $\mathrm{Cu} /$ low- $\kappa$ interconnects [59]. Thanks to the tunability and high brightness of synchrotron sources, synchrotron radiation-XPS (SR-XPS) can be used to study chemical composition of ultra-thin films and buried interfaces [60]. Progress in synchrotron sources has also led to the development of Photoelectron Emission Microscopy imaging with spatial resolution around $250 \mathrm{~nm}[61,62]$. 


\section{Glossary}

\begin{tabular}{|c|c|}
\hline AES & Auger Electron Spectroscopy \\
\hline ALD & Atomic Layer Deposition \\
\hline CD & Critical Dimension \\
\hline CD-SAXS & $\begin{array}{l}\text { Critical Dimension- Small Angle } \\
\text { X-ray Scattering }\end{array}$ \\
\hline CET & $\begin{array}{l}\text { Capacitance Equivalent Gate } \\
\text { Thickness }\end{array}$ \\
\hline CMOS & Complementary MOS \\
\hline CMP & Chemical and Mechanical Polishing \\
\hline CVD & Chemical vapour Deposition \\
\hline DPN & Decoupled Plasma Nitridation \\
\hline ECD & Electrochemical Deposition \\
\hline EOT & Equivalent Oxide Thickness \\
\hline EP & Ellipsometric Porosimetry \\
\hline ERDA & Elastic Recoil Detection Analysis \\
\hline FWHM & Full Width at Half Maximum \\
\hline GI-SAXS & $\begin{array}{l}\text { Grazing Incidence- Small Angle } \\
\text { X-ray Scattering }\end{array}$ \\
\hline JCPDS & $\begin{array}{l}\text { Joint Committee on Powder } \\
\text { Diffraction Standards }\end{array}$ \\
\hline LDD & Lightly Doped Drain \\
\hline LWR & Line Width Roughness \\
\hline MIM & Metal Insulator Metal \\
\hline MOCVD & $\begin{array}{l}\text { Metal Organic Chemical Vapor } \\
\text { Deposition }\end{array}$ \\
\hline MOS & Metal-Oxide-Semiconductor \\
\hline NIST & $\begin{array}{l}\text { National Institute of Standards } \\
\text { and Technology }\end{array}$ \\
\hline NMOS & n-channel MOS transistor \\
\hline PAS & Positron Annihilation Spectroscopy \\
\hline PEALD & $\begin{array}{l}\text { Plasma Enhanced Atomic Layer } \\
\text { Deposition }\end{array}$ \\
\hline PECVD & $\begin{array}{l}\text { Plasma Enhanced Chemical Vapour } \\
\text { Deposition }\end{array}$ \\
\hline PMOS & p-channel MOS transistor \\
\hline PVD & Physical Vapour Deposition \\
\hline $\mathbf{R F}$ & Radio-Frequency \\
\hline RTA & Rapid Thermal Anneal \\
\hline RTN & Rapid Thermal Nitridation \\
\hline SE & Spectroscopic Ellipsometry \\
\hline SOI & Silicon On Insulator \\
\hline TEM & Transmission Electron Microscope \\
\hline ToF-SIMS & $\begin{array}{l}\text { Time of Flight Secondary Ion Mass } \\
\text { Spectrometry }\end{array}$ \\
\hline TXRF & Total X-ray Fluorescence \\
\hline ULK & Ultra Low- $\kappa$ dielectrics \\
\hline XPS & X-ray Photoelectron Spectroscopy \\
\hline XRD & X-ray Diffraction \\
\hline XRF & X-ray Fluorescence \\
\hline XRR & X-ray Reflectivity \\
\hline XRT & X-ray diffraction Topography \\
\hline
\end{tabular}

The research work described in this paper was partially supported by SEANET (IST-027982) and PULLNANO (IST026828) European projects. These studies would not have been achieved without the close and efficient collaborations with J.-P. Gonchond, E. Deloffre, S. Pokrant, L. Plantier, S. Bonnetier, J. Bienacel, N. Emonet, M. Grosjean, F. Pernot, I. Mazor, W. Betz, T. Larson, D. Kurtz, K. Kozaczek and numerous experts from STMicroelectronics and Crolles2Alliance.

\section{References}

1. Y. Tian, W. Li, J. Chen et al., Rev. Sci. Instrum. 79, 103708 (2009)

2. P. Bleuet, P. Cloetens, P. Gergaud et al., Rev. Sci. Instrum. 80, 56101 (2009)

3. M. Hanke, M. Dubslaff, M. Schmidbauer et al., Appl. Phys. Lett. 92, 193109 (2008)

4. S.M. Polvino, C.E. Murray, O. Kalenci et al., Appl. Phys. Lett. 92, 224105 (2008)

5. International Technology Roadmap for Semiconductors, http://public.itrs.net

6. A.C. Diebold (ed.), Handbook of silicon semiconductor metrology (Marcel Dekker, New-York, 2001)

7. A. Gril, V. Patel, K.P. Rodbell et al., J. Appl. Phys. 94, 3427 (2003)

8. A.V. Zozulya, O.M. Yefanov, I.A. Vartanyants et al., Phys. Rev. B 78, 121304 (2008)

9. T. Suzuki, K. Omote, Y. Ito et al., Thin Solid Films 515, $2410(2006)$

10. A. Danel, N. Cabuil, T. Lardin et al., Spectrochim. Acta B 63, 1375 (2008)

11. L.G. Parrat, Phys. Rev. 95, 359 (1954)

12. C.E. Murray, M. Sankarapandian, S.M. Polvino et al., Appl. Phys. Lett. 90, 171919 (2007)

13. http://www. jordanvalley.com

14. C.R. Brundle, A.D. Baker, T.D. Thomas, Phys. Today 32, $62(1979)$

15. http://www.revera.com

16. G.M. Cohen, P.M. Mooney, H. Park et al., J. Appl. Phys. 93, 245 (2003)

17. I.V. Antonova, V.P. Popov, J. Bak-Misiuk et al., J. Electrochem. Soc. 149, G490 (2002)

18. M.S. Goorsky, P. Feichtinger, H. Fukuto et al., Phil. Trans. R. Soc. Lond. A 357, 2777 (1999)

19. C. Emons, HYMNE MEDEA+, Project Report (2005)

20. S. Pokrant, R. Pantel, M. Cheynet, Microelectron. Eng. 83, 2364 (2006)

21. T. Yamaguchi, K. Kashihara, T. Okudaira et al., IEEE Trans. Electron. Dev. 56, 206 (2009)

22. L. Capello, T.H. Metzger, V. Holy et al., J. Appl. Cryst. 39, 571 (2006)

23. D. Babonneau, S. Peripolli, M.-F. Beaufort et al., J. Appl. Cryst. 40, s350 (2007)

24. L. Capello, F. Rieutord, A. Tauzin et al., J. Appl. Phys. 102, 26106 (2007)

25. A. Uedono, K. Ikeuchi, T. Otsuka et al., J. Appl. Phys. 99, 54507 (2006)

26. M.A. Douglas, S. Hattangady, K. Eason, J. Electrochem. Soc. 147, 1893 (2000)

27. F.J. Himpsel, F.R. McFeely, A. Taleb-Ibrahimi, Phys. Rev. B 38, 6084 (1988)

28. M.P. Seah, S.J. Spencer, Surf. Int. Anal. 35, 515 (2003)

29. S. Tougaard, J. Vac. Sci. Technol. A 21, 1081 (2003)

30. T. Hattori, H. Nohira, S. Shinagawa et al., Microelectron. Reliab. 47, 20 (2007)

31. M. Bidaud, J.-P. Carrère, F. Bœuf et al., Proc. Analytical Techniques for Semiconductor Materials and Process Characterization IV (ALTECH 2003), Paris, France, 2003 
32. J. Bienacel, D. Barge, M. Bidaud et al., Mater. Sci. Semicond. Process. 7, 181 (2004)

33. S. Bonnetier, B. Imbert, M. Hopstaken et al., Microelectron. Eng. 84, 2528 (2007)

34. K. Hoummada, C. Perrin-Pellegrino, D. Mangelinck, J. Appl. Phys. 106, 63511 (2009)

35. C. Detavernier, C. Lavoie, Appl. Phys. Lett. 84, 3549 (2004)

36. J.-P. Gonchond, C. Wyon, F. Cacho et al., Proc. Characterization and Metrology for ULSI Technology (2005), p. 182

37. C. Lavoie, F. D'Heurle, C. Detavernier et al., Microelectron. Eng. 70, 144 (2003)

38. D. Deduytsche, C. Detavernier, L. Van Meirhaeghe et al., J. Appl. Phys. 98, 33526 (2005)

39. S. Zollner, R.B. Gregory, M.L. Kottke et al., Proc. Frontiers of Characterization and Metrology for Nanoelectronics (2007), p. 337

40. K. Maex, M.R. Baklanov, D. Shamiryan et al., J. Appl. Phys. 93, 8793 (2006)

41. C.-H. Hsua, U-Ser Jenga, Hsin-Yi Leea et al., Thin Solid Films 472, 323 (2005)

42. T.K. Goh, T.K.S. Wong, Microelectron. Eng. 75, 330 (2004)

43. L. Plantier, J.-P. Gonchond, F. Pemot et al., Proc. Frontiers of Characterization and Metrology for Nanoelectronics (2007), p. 347

44. H.-J. Lee, E.K. Lin, H. Wang et al., Chem. Mater. 14, $1845(2002)$

45. H.-J. Lee, C.L. Soles, D. Liu et al., J. Appl. Phys. 95, 2355 (2004)

46. H.-J. Lee, C.L. Soles, D.-W. Liu et al., J. Appl. Phys. 100, $064104(2006)$

47. M. Damon, T. Chevolleau, T. David et al., J. Vac. Sci. Technol. B 26, 1964 (2008)
48. E. Huang, M.F. Toney, W. Volksen et al., Appl. Phys. Lett. 81, $2232(2002)$

49. D.J. Kinning, E.J. Thomas, Macromolecules 17, 1712 (1984)

50. C. Wyon, D. Delille, J.-P. Gonchond et al., Thin Solid Films 450, 84 (2004)

51. C. Wyon, J.-P. Gonchond, D. Delille et al., Appl. Surf. Sci. 253, 21 (2006)

52. T. Hara, K. Sakata, A. Kawaguchi et al., Electrochem. Solid-State Lett. 4, 11, C81 (2001)

53. T. Aoyama, S. Sadai, Y. Okayama et al., J. Electrochem. Soc. 143, 977 (1996)

54. G. Dollinger, A. Bergmaier, L. Goergens et al., Nucl. Instrum. Meth. Phys. Res. B 219, 200 (2004)

55. E. Deloffre, C. Wyon, M. Gros-Jean, in 207th ECS Meeting, Quebec City, Canada, 2005, Rep. Tech. Prog. 501, Abstract 434, http://www.electrochem. org/meetings/biannual/207/abstracts/tp/ reportTechProg_501_H1.html

56. G.-Y. Choi, S.K. Kim, S.Y. Lee et al., J. Electrochem. Soc. 156, G71 (2009)

57. S. Jeannot, A. Bajolet, J.-P. Manceau et al., Proc. Int. Electron Devices Meeting-IEDM (2007), p. 997

58. C. Wang, K.-W. Choi, W.-E. Fu et al., Proc. IEEE/SEMI Advanced Semiconductor Manufacturing Conf. (2008), p. 142

59. E. Zschech, W. Yun, G. Schneider, Appl. Phys. A 92, 423 (2008)

60. C.J. Wilson, C. Zhao, L. Zhao et al., Proc. Int. Interconnect Technol. Conf. (2009), p.72

61. Y. Narita, F. Hirose, M. Nagato et al., Thin Solid Films 517, 209 (2008)

62. A. Bailly, O. Renault, N. Barrett et al., J. Phys.: Condens. Matter 21, 314002 (2009) 